\title{
The Effectiveness of Acceptance and Commitment-based Parenting education on Children's Anxiety and the Parenting Stress of Mothers
}

\author{
Kowsar Tardast ${ }^{1}$, Abbas Amanelahi ${ }^{1 *}$, Gholamreza Rajabi ${ }^{1}$, Khaled Aslani ${ }^{1}$, Khdije Shiralinia $^{1}$ \\ 1. Shahid Chamran University of Ahvaz, Ahvaz, Iran
}

Received: 5 July 2020

Accepted for publication: 20 February 2021

[EPub a head of print-1 March 2021]

Payesh: 2021; 20 (1):91-107

\begin{abstract}
Objective (s): The present study aimed to evaluate the effect of acceptance and commitment-based parenting education on children's anxiety and parenting stress of mothers.

Methods: Non-congruent multiple baseline experimental single-case studies were used as the method in the current study. Three anxious children and their mothers were selected through purposeful sampling in Ahvaz, Iran. The effectiveness of acceptance-and-commitment-based parenting education protocol was carried out in three phases (baseline assessment, 12 session treatment, and 1-month follow-up) by using the Spence Children's Anxiety Scale-Parent Form and the Parenting Stress Index-Short Form). The data were analyzed by visual mapping, reliable change index and recovery percentage formula. The direction changes, PND, and POD were the most important variables of visual analysis of trend changes.

Results: The mothers and children's reliable change indices were significant in all the instances except for the second mother and child. The subjects' recovery percentage showed that the results of the reliable change indices and recovery percentages are consistent.

Conclusion: Acceptance and commitment-based parenting education can reduce parenting stress and children's anxiety by increasing parent's acceptance, mindfulness, and moving toward parenting values.
\end{abstract}

Key Words: acceptance and commitment-based parenting, anxiety, parenting stress

\footnotetext{
* Corresponding author: Shahid Chamran University of Ahvaz, Ahvaz, Iran

E-mail: a.amanelahi@scu.ac.ir
} 


\title{
اثربخشى آموزش فرزنديرورى مبتنى بر بذيرش و تعهد بر اضطراب كودكان و استرس فرزنديرورى مادران
}

\author{
كوثر تردست'، عباس امان الهى '، غلامرضا رجبى'؛ خالد اصلانى'، خديجه شيرالى نيا' \\ I. دانشكده علوم تربيتى و روانشناسى، دانشَاه شهيد جمران اهواز، اهواز، ايران \\ تاريخ دريافت: ت ت ت

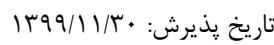

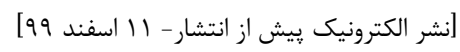

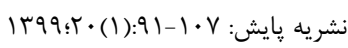

جكيده

مقدمه: هدف يُزوهش حاضر بررسى آموزش فرزنديرورى مبتنى بر يذيرش و تعهد بر اضطراب كودكان و استرس فرزنديرورى مادران بود.

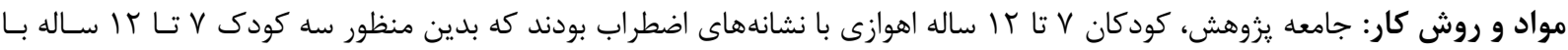

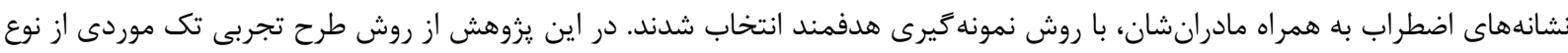

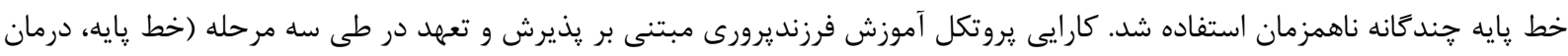

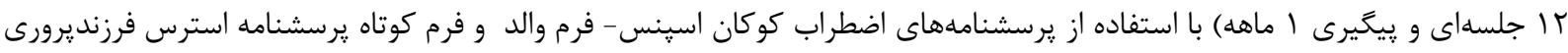

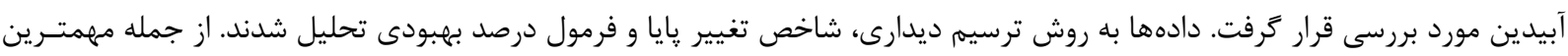

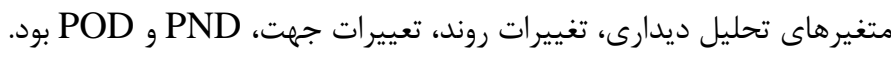

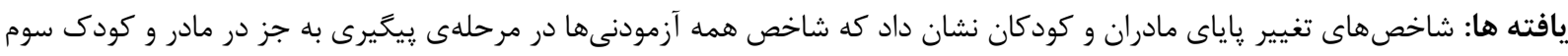

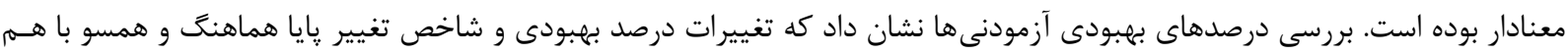

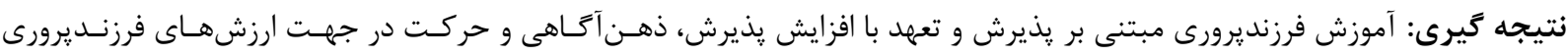

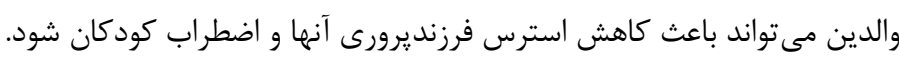

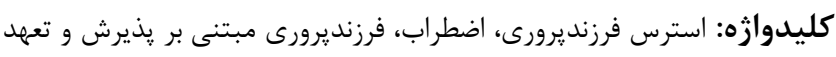

كد اخلاق: IR.ACECR.IBCRC.REC.1395.6 
كه اين تأثيريذيرى هم نشأت كرفته از تحقيقات انجام شـده توسط ذهـ

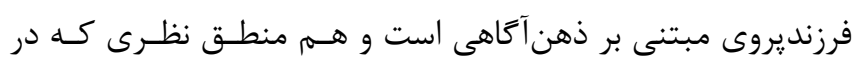

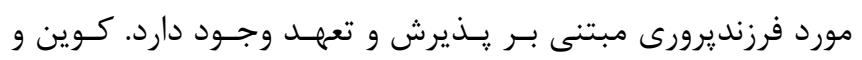

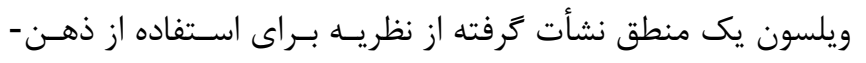

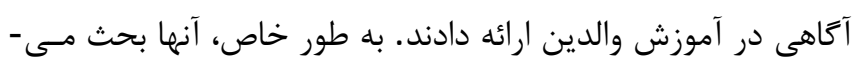

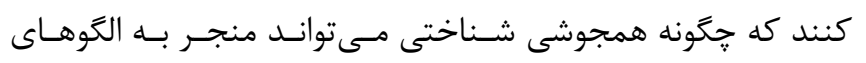

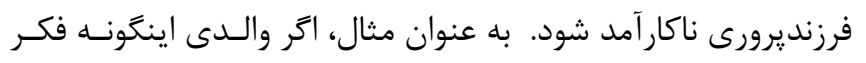

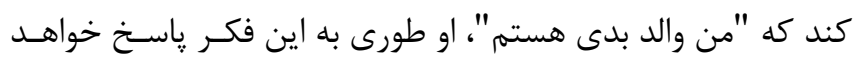

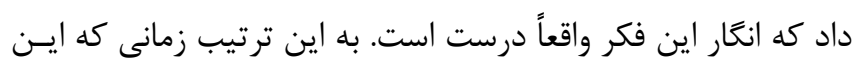

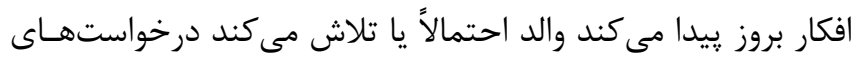

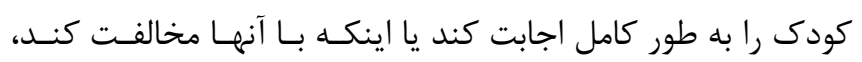

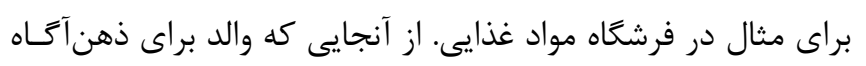

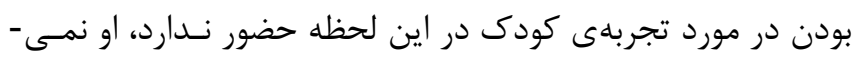

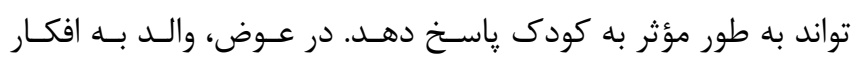

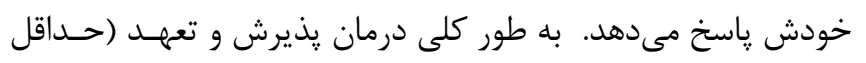

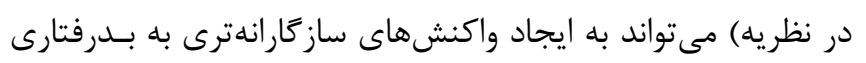

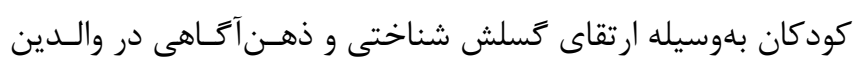

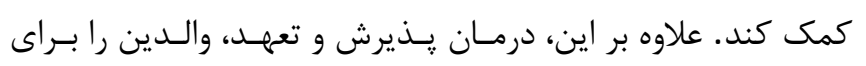

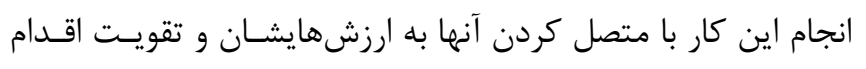

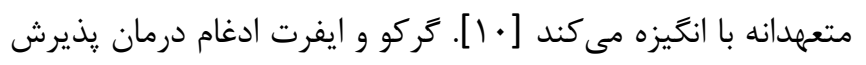

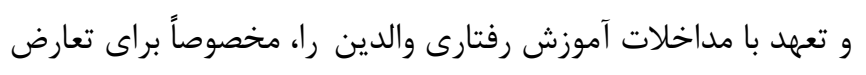

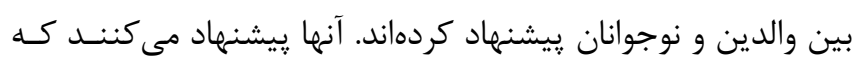

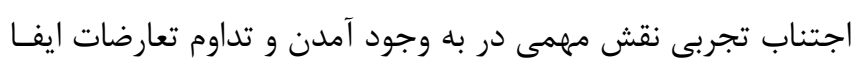

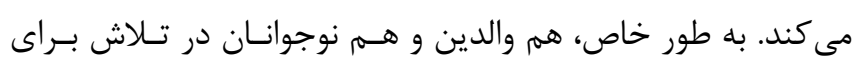

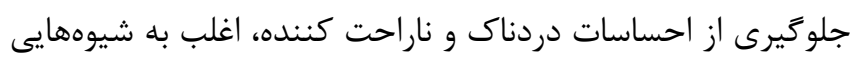

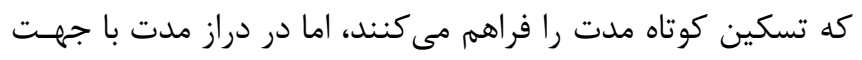

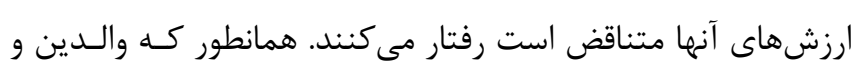

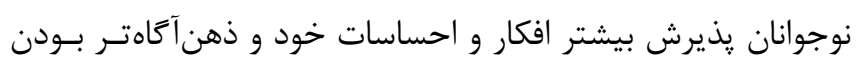

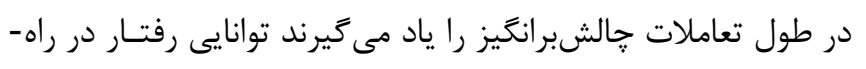

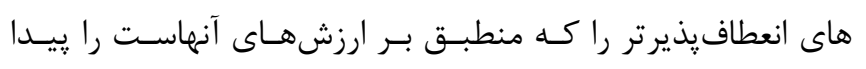
خواهند كرد [11]

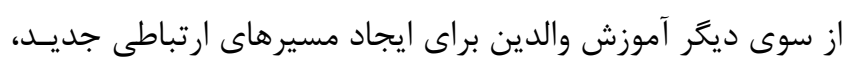

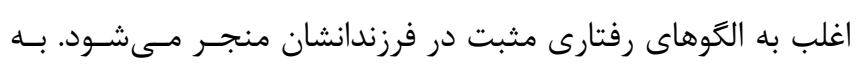

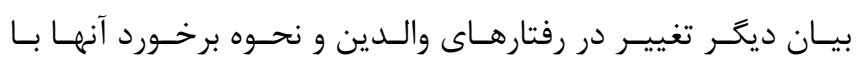

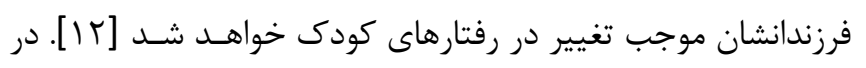

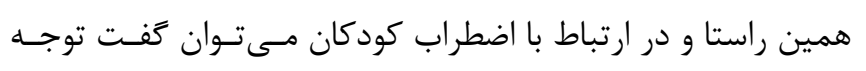

\section{مقدمه}

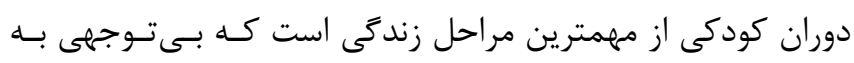

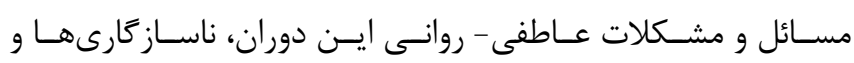

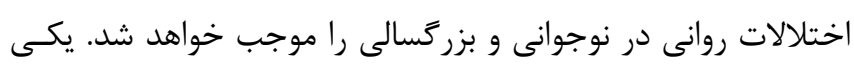

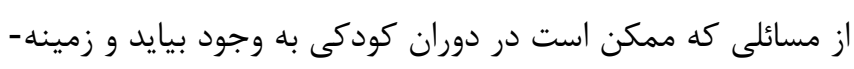

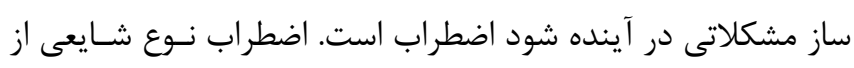

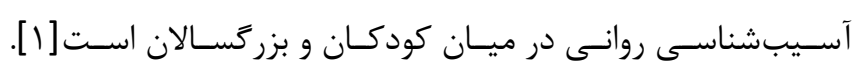

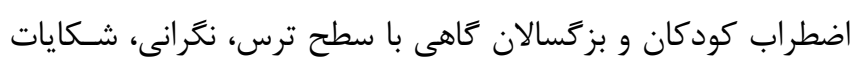

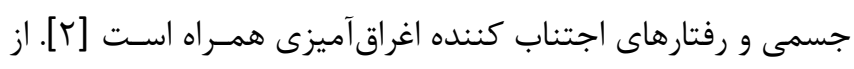

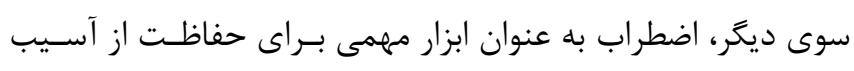

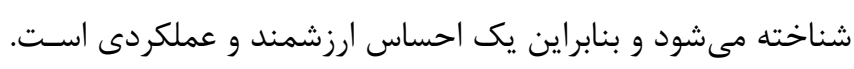

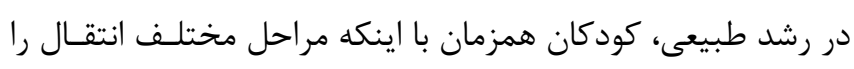

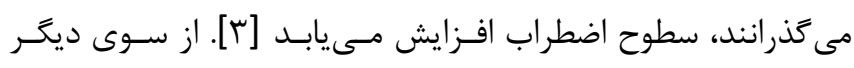

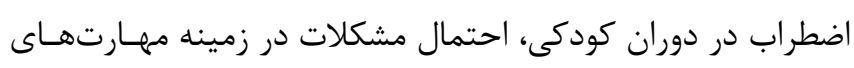

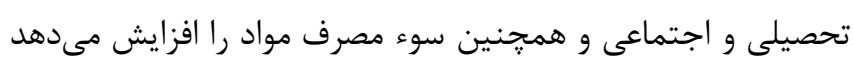

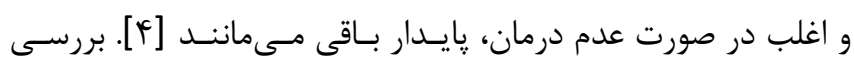

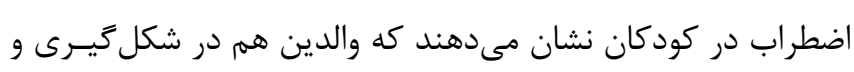

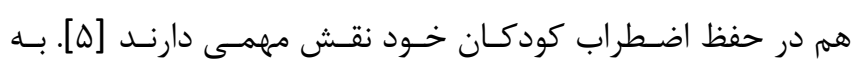

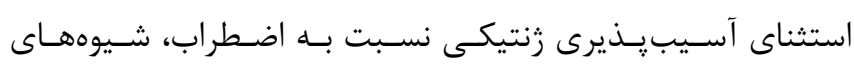

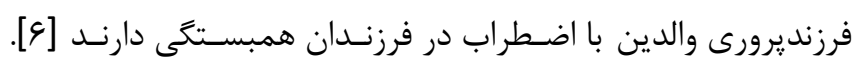

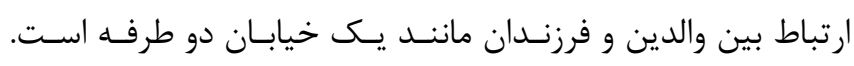

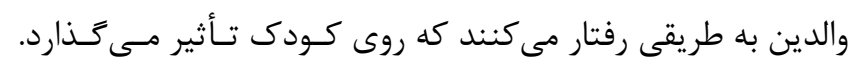

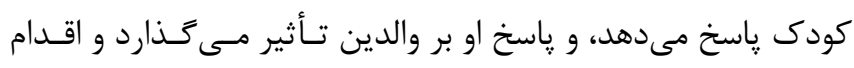

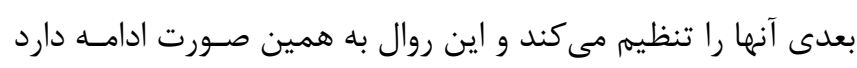

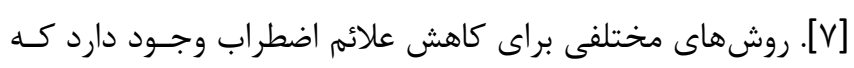

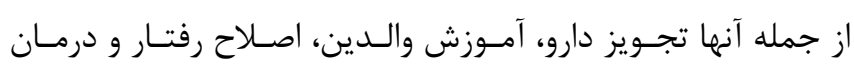

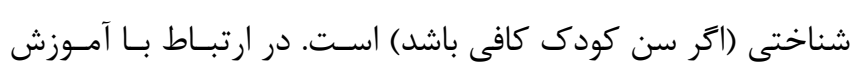

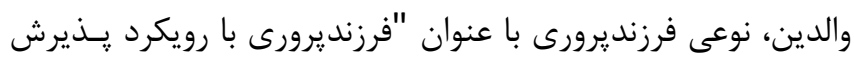

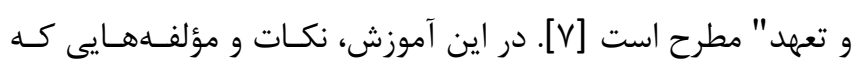

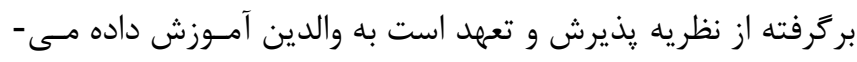

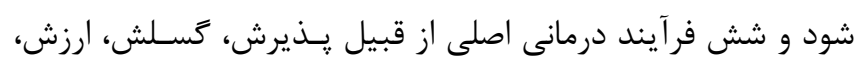

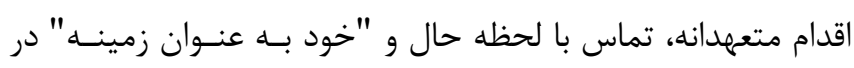

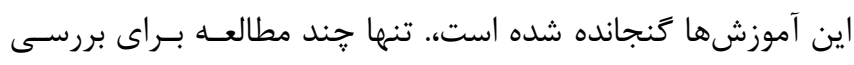

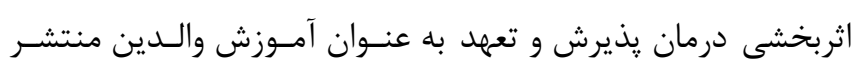

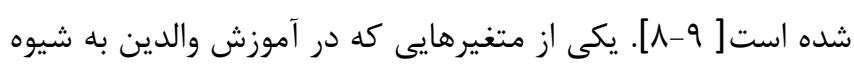

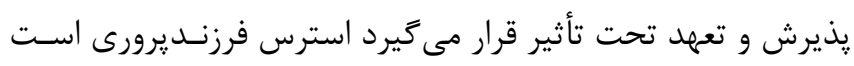


درمانى بالينى است [•r]]. در اين گونه طرحها شرايط آزمايشى بــهـ

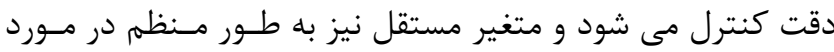

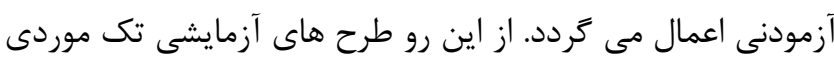

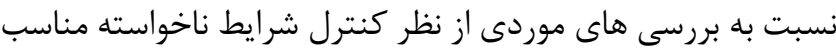

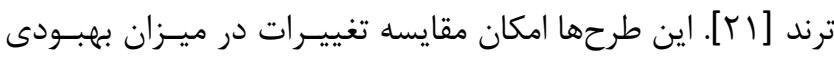

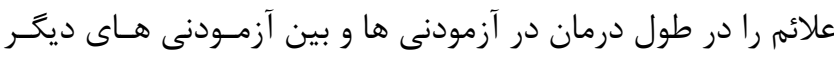

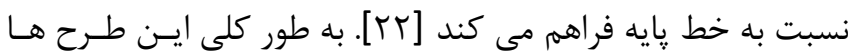

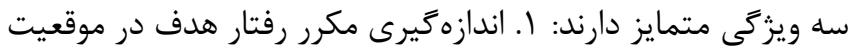

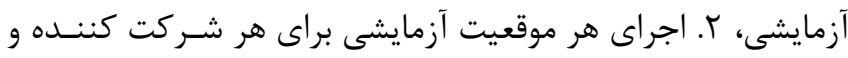

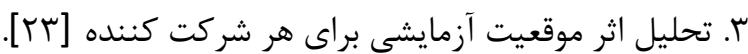

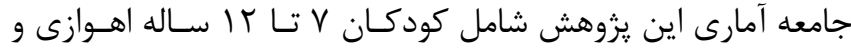

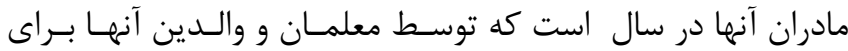

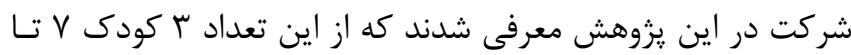

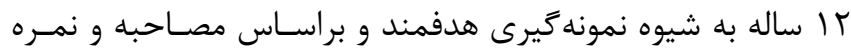

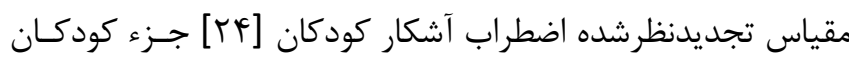

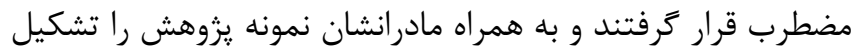

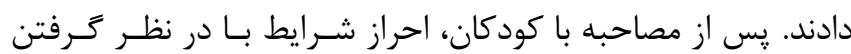

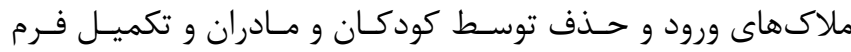

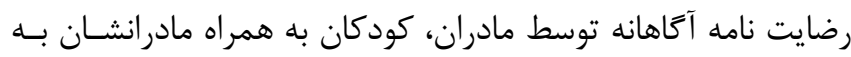

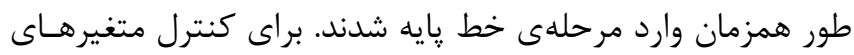

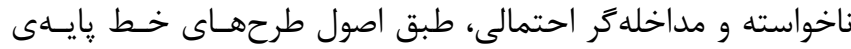

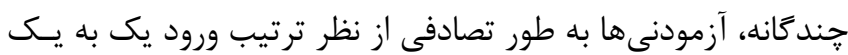

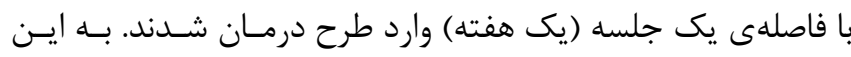

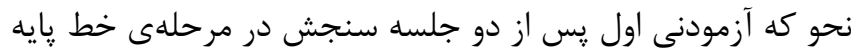

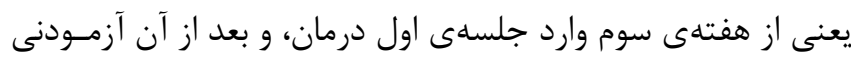

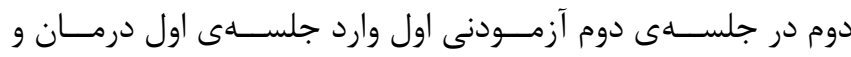

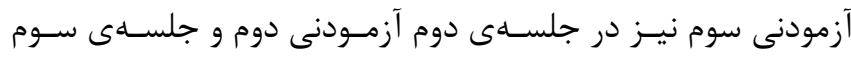

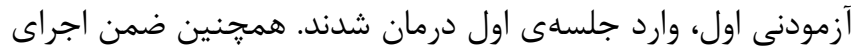

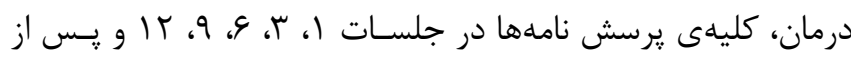
درمان در فاصلهى زمانى يك ماه مرحلهى بي زيخيرى انجام شد.

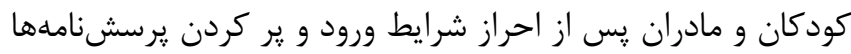

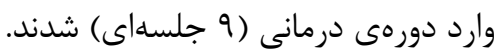

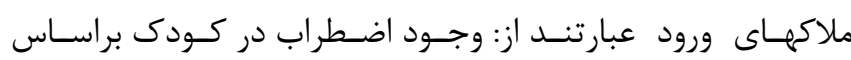
مصاحبه و كسب نمرهى 19 و يا بالاتر در مقيـاس اضـطراب آشـكار

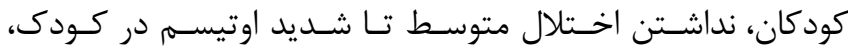
نداشتن مشكلات يادگيرى متوسط تا شديد در كودى يا مـادر، دارا
اساسى والدين نسبت به رفتارهاى منفى فرزند ممكن است بــه طـور

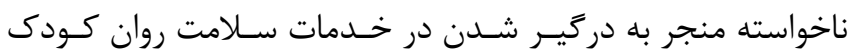

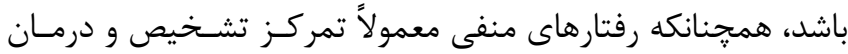

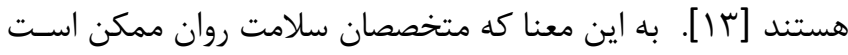

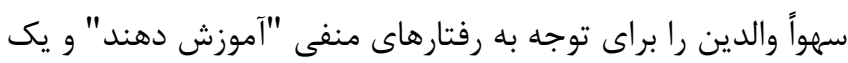

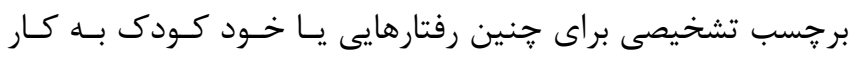

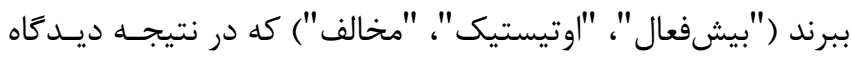

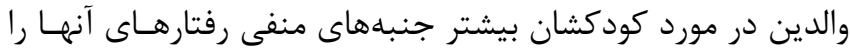

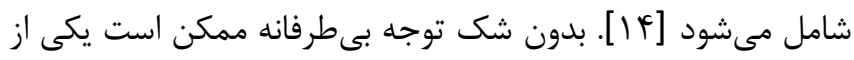

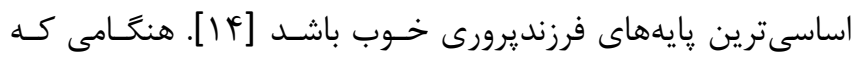
والدين نسبت به تمامى اظهارات فرزندشان بدون قضاوت توجه مى

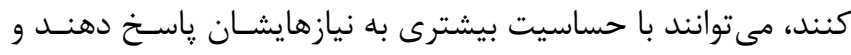

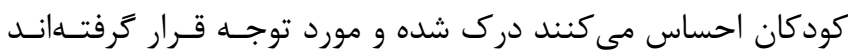

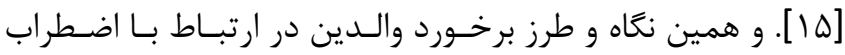
فرزندشان، فشار كمترى بر كودى خواهد آورد و كودى بهتر خواهد

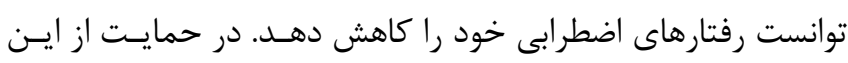

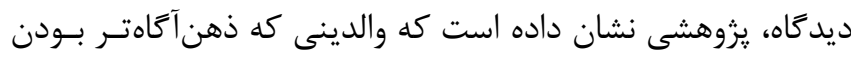
را كزارش مى دهند مهارتهاى فرزنديرورى مثبت ترى ران انشان مسى

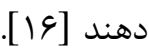

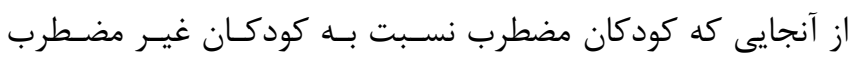

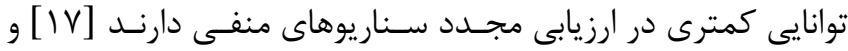

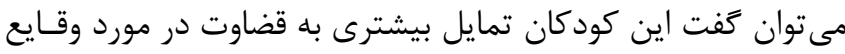

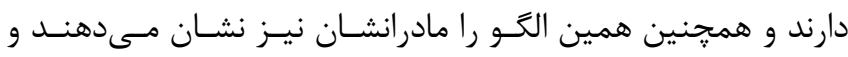

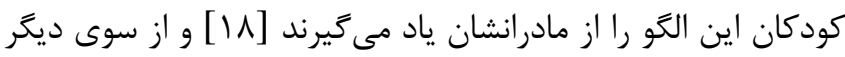

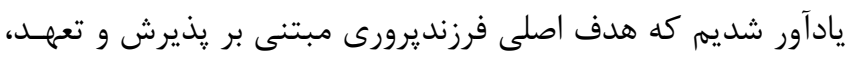

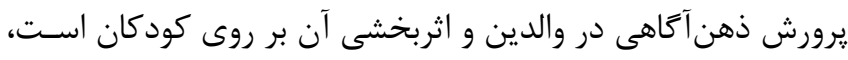

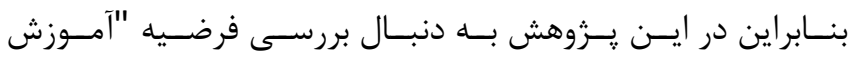
فرزنديرورى مبتنى بر يذيرش و تعهد بر متغيرهاى اضطراب كودكان

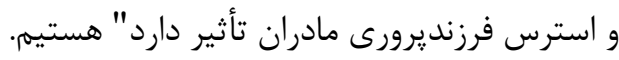

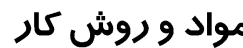

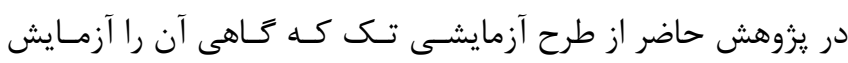

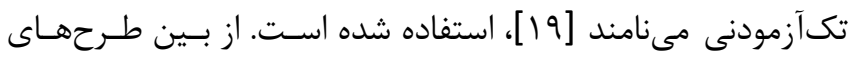

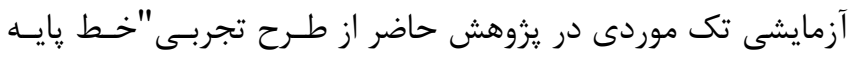

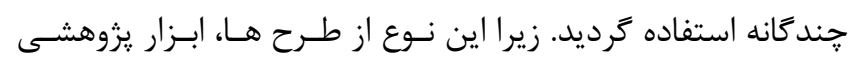

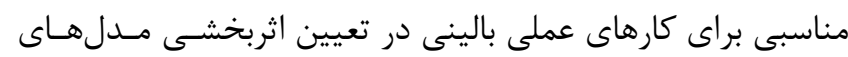




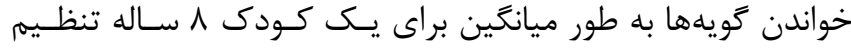
شده است. هدف يرسشنامه بررسى اضطراب آشكار كودكان از ابعـاد

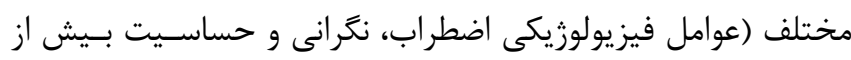

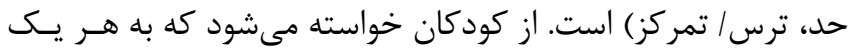

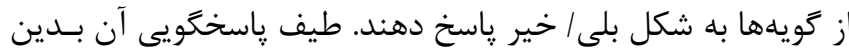

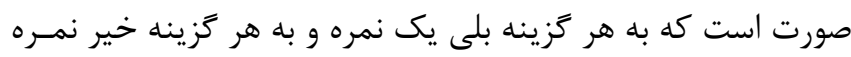

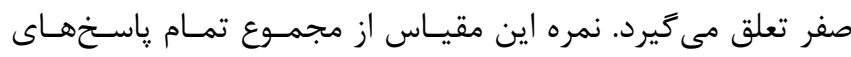

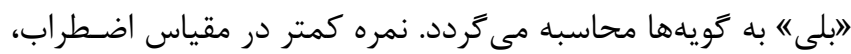

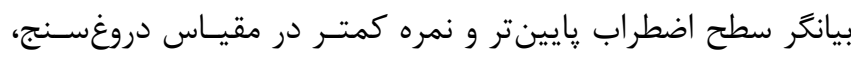

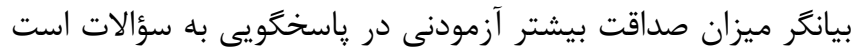

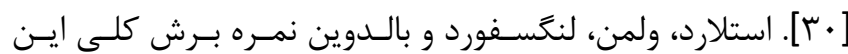

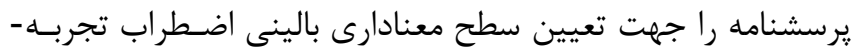

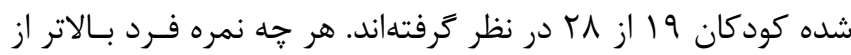

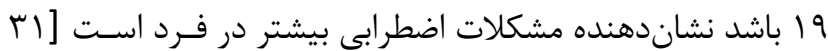

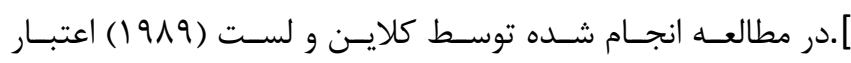

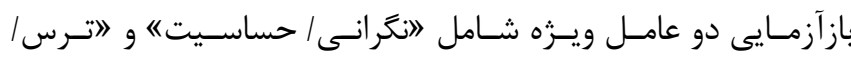

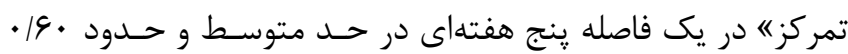

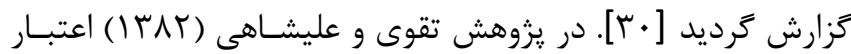

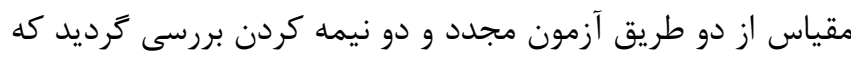

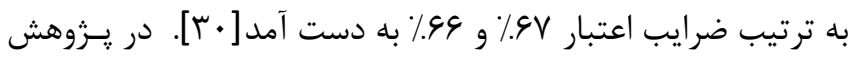

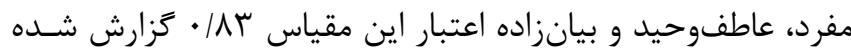

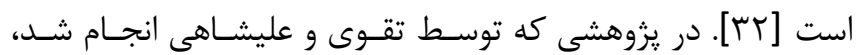

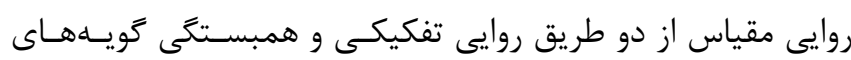

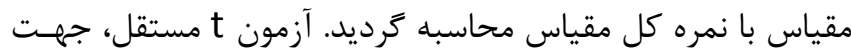
بررسى روايى تفكيكى بين دو گروه بيمار ان اضطرابى و افراد بهنجـار نشان داد كه مقياس اضطراب آشكار كودكان قادر است بين دو كرو تروه

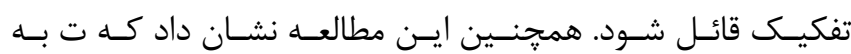

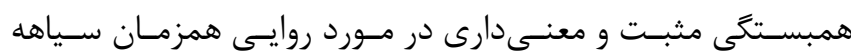
حالت- صفت اضطراب كودكان و مقياس اضـطر دراب آشـكار كودكـان دست يافتند [بس]. مقياس استرس فرزنديرورى (فرم كوتاه): فرم كوتاه مقياس اسـترس

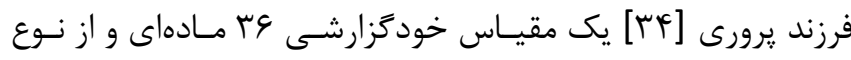

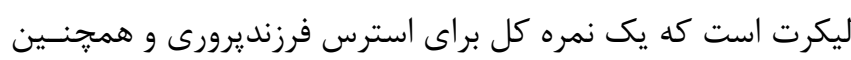

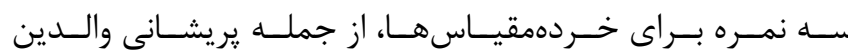
parent-(parental distress) (child dysfunctional interaction
بودن مدرك تحصيلى دييلم و بالاتر در مادران و عدم استفاده از هر

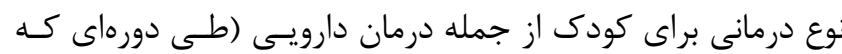

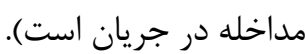

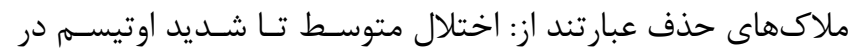

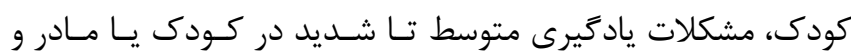

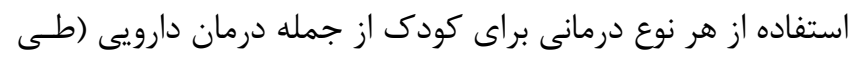

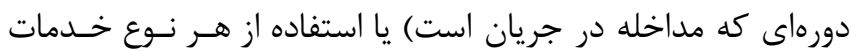
روانشناختى و مشاورهاى از طرف مادر.

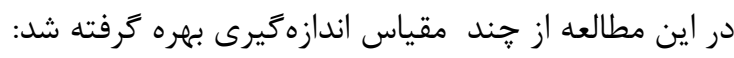

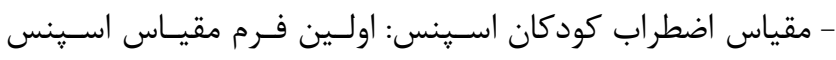

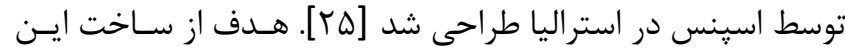

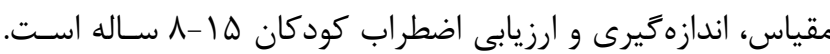

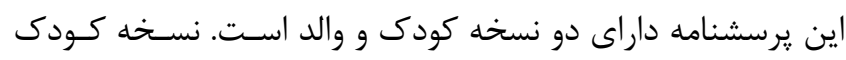

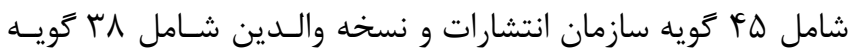

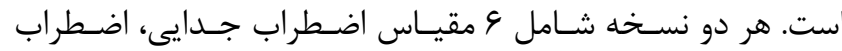

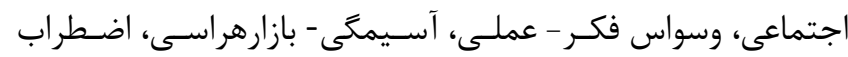

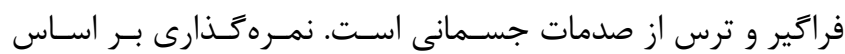

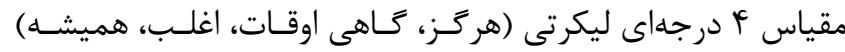

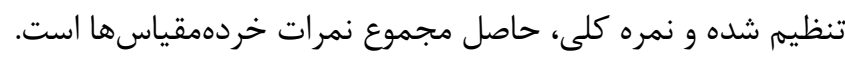

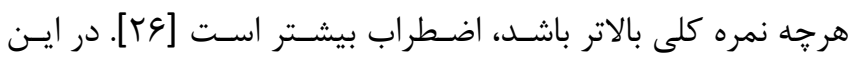

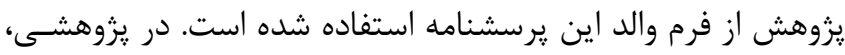

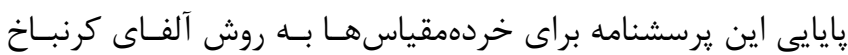

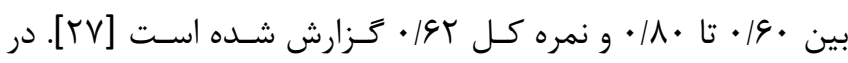

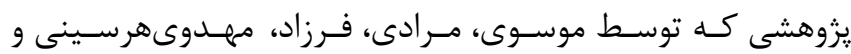

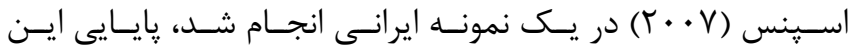

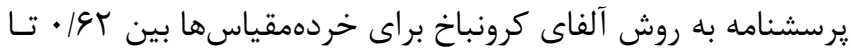

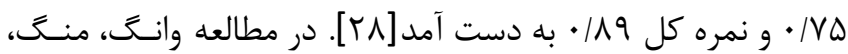

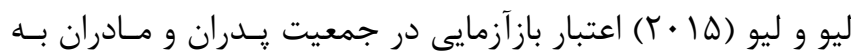

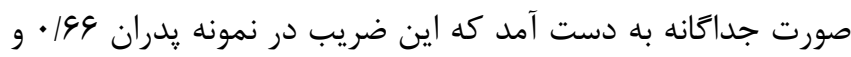

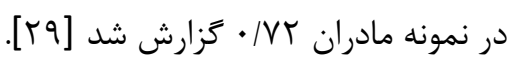
- مقياس تجديدنظرشده اضطراب آشكار كودكان: يرسشنامه لآنحـهـ

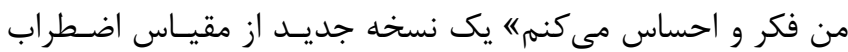

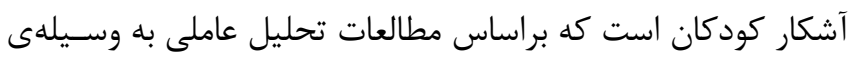

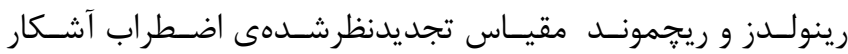

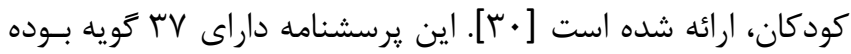

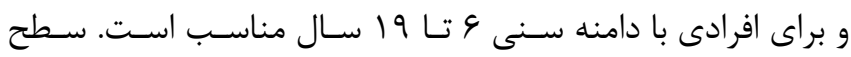




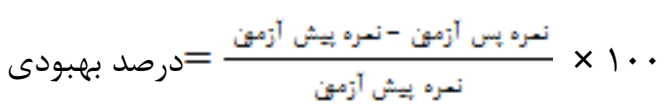

براى سنجش عملياتى كارايى بهبود تشخيصى از مصاحبه سـاختار -

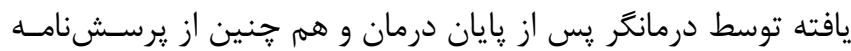
ها استفاده مىشود تا بهبود تشخيصى سنجيده شود. براى سـنجش إنش

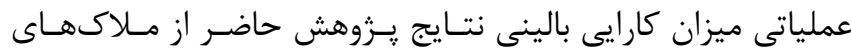
اينگرام، هيز و اسكات استفاده خواهد شد كه عبارتند ازي: 1- اندازه تغيير (جقدر تغيير در هدفهاى اصلى درمان رخ داده است؟؟)

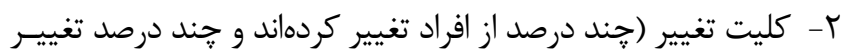

نكردهاند؟)

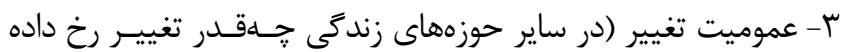

است؟؟)

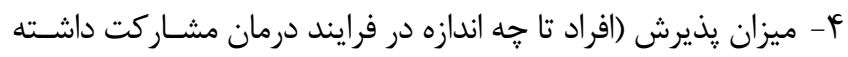
و آن را به پايان رساندهاند؟) ه- ايمنى (آيا در اثر درمان سلامت روانسى و جسـمانى بيمـاران كـاهش

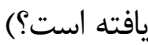
צ- ثبات (دستاوردهاى درمان جهقدر دوام داشتهاند؟) [^ץ]. شماره ا آمده است.

يافتهها همانگونه كه در جدول شماره r آمده است دو يسر و يك دختـر در اين :روهش شركت كردند كه دامنه سنى آنهـا بـين 1 تـا • ا سـال بود. همه مادران شركت كننده در اين يزوهش حداقل داراى مـدرى

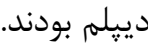
در جدول شماره ץ به ترتيب آمارههـاى توصـيفى آزمـودنىهـا در

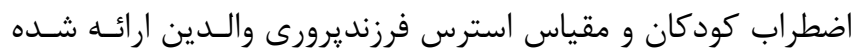
است. همانكونه كه در جدول شماره ب مشاهده مسىشـود. در مـورد

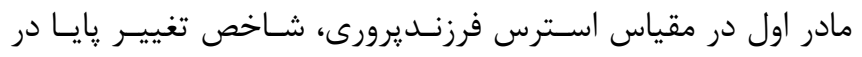

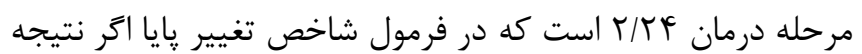

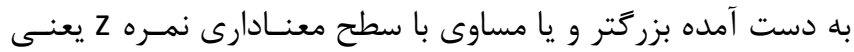

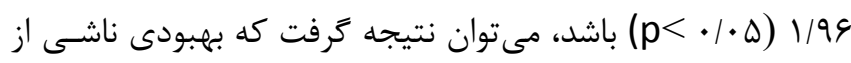

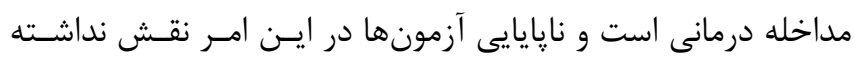

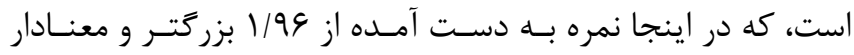

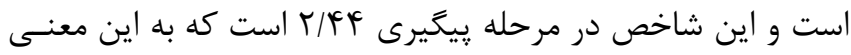

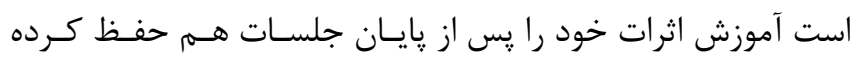

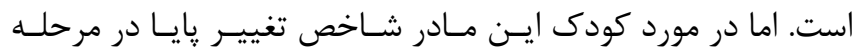

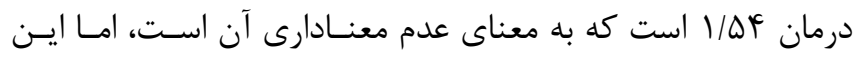

به دست مى آيـد. از ياسـخ دهنــدَان خواسـته (difficult child)

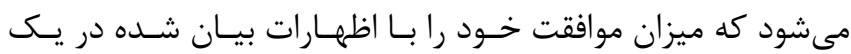

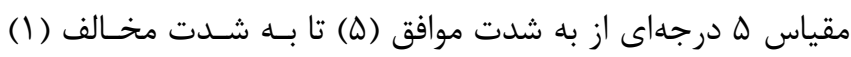

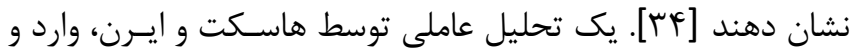

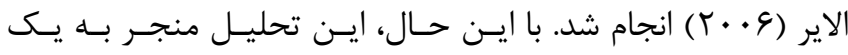

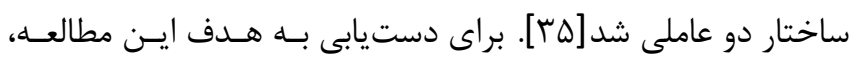
نمره كل اين مقياس استفاده مىشـود. در يزوهشـى ضـريب اعتبـار

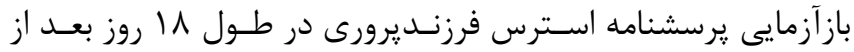

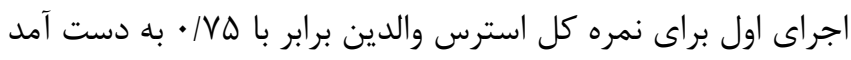

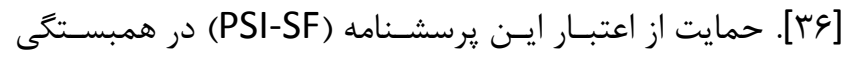
بين نمرات كل فرم كوتاه مقياس اسـترس فرزنـديرورى (r = / و نمره كل در نسخه كامـل اسـترس فرزنـديرورى (PSI-SF)

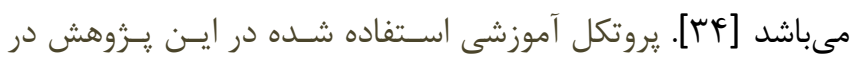

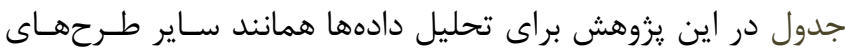
موردى از ترسيم جشمى (visual inspeetion) (تحليـل نمـودار)،

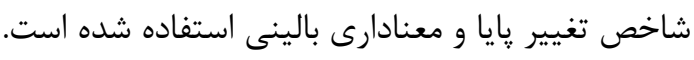
نخستين راهبرد يا روش براى تحليل نتايج حاصل، اسـتفاده از روش

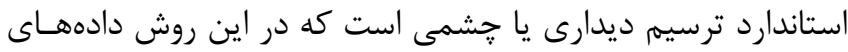
يثوهش و عملكرد بيماران به واسطه الكوهاى ترسيم ديدارى بررسى ديى

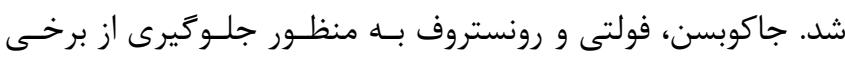
خطاهاى احتمالى در تعيين نقطه بـرش ناشـى از هميوشى و و عـدم رون

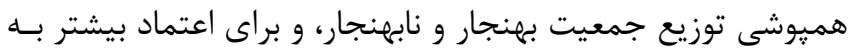

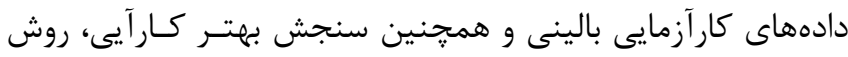

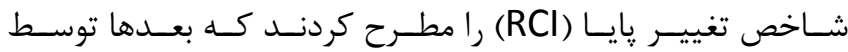

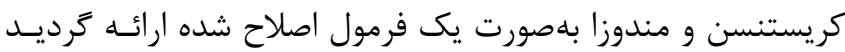

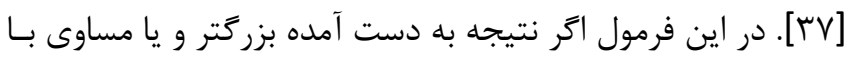

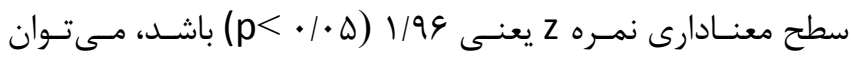

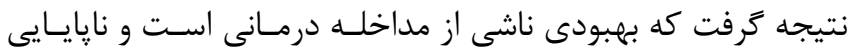
آزمونها در اين امر نقش نداشته است. شيوه ديخرى كه در اين :زروهش استفاده شد روش معنادارى بالينى است. اگر درمان بتواند آماج تغيير يا بهبود معنادار بالينى را برگشت

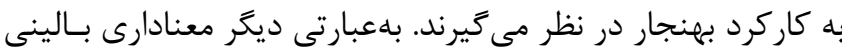

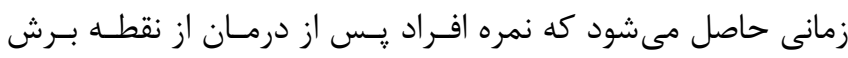

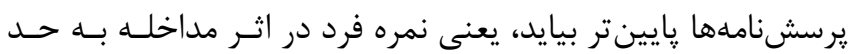
نمره افراد سالم برسد. براى عينى سازى ميزان بهبودى در آماجهاى

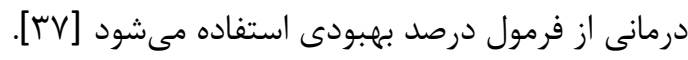


كَيرند [rr]. براى محاسبه ميانه يك سرى داده، مقادير نقاط دادهها

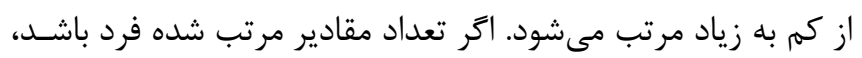

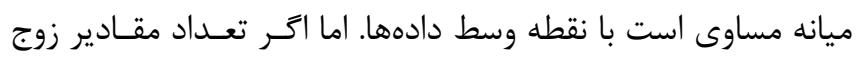
باشد، ميانه از طرق ميانگين دو نقطه ميانى به دست مئ آيد. سـيس

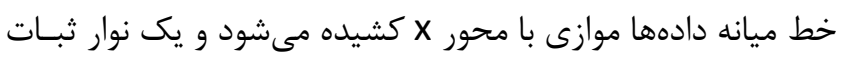

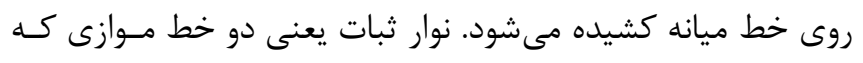

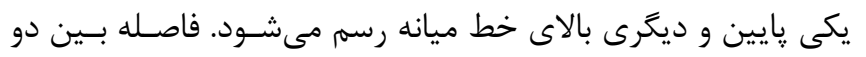

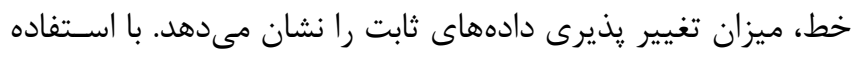

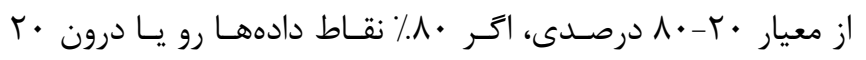

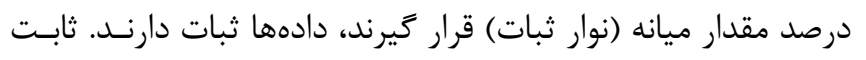

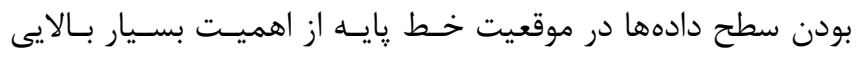

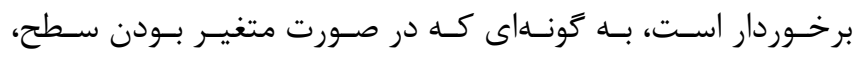

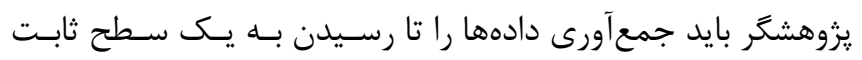

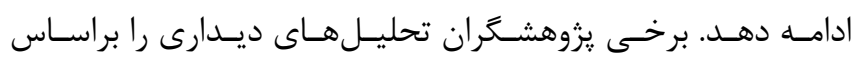

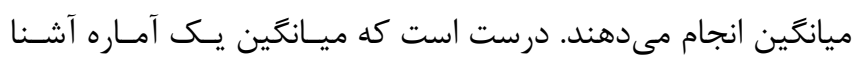

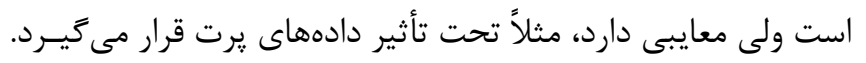

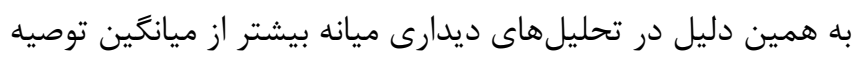

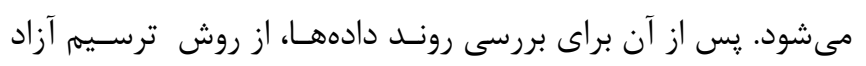

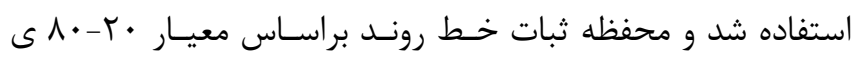

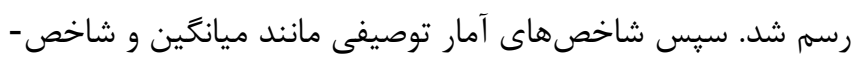

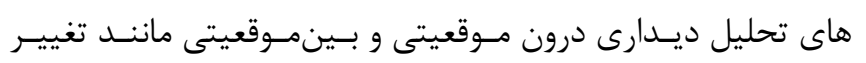

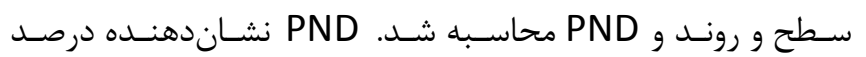

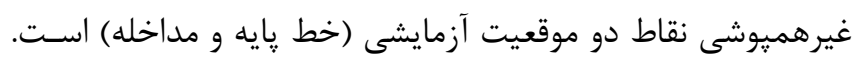

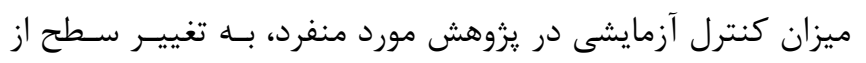

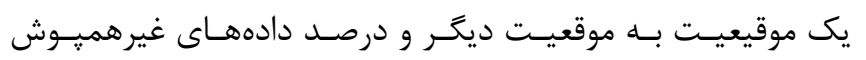

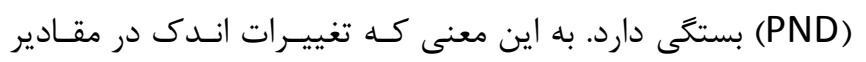

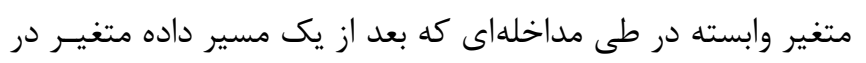

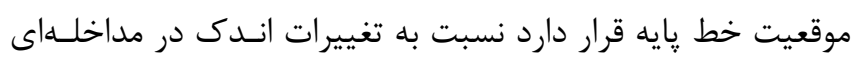

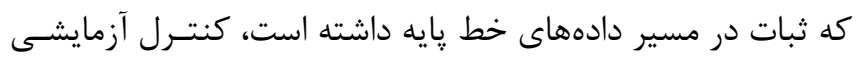

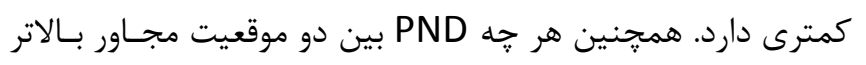

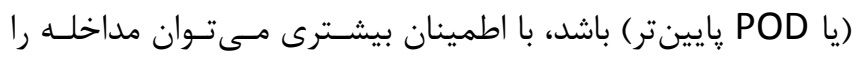

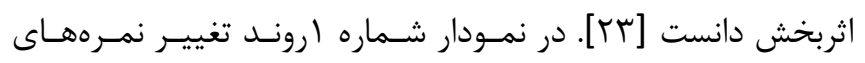

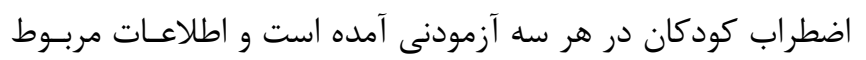

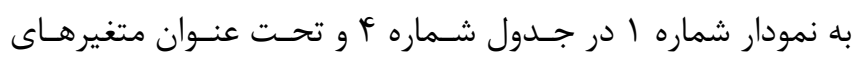

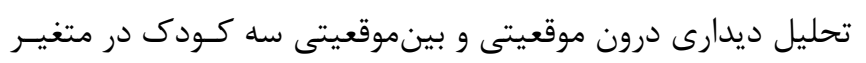

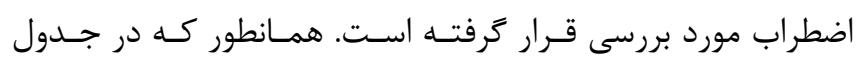

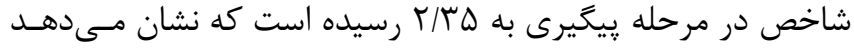

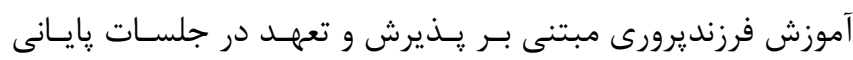

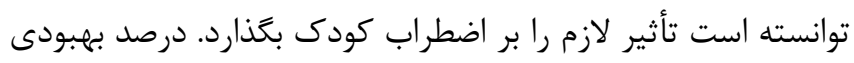

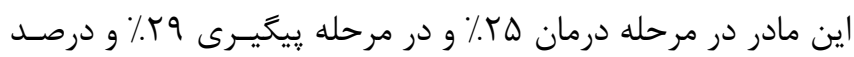

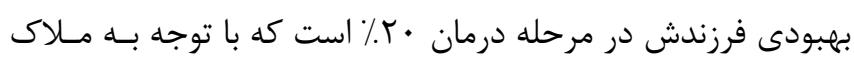

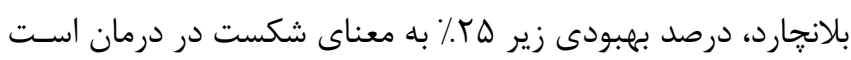

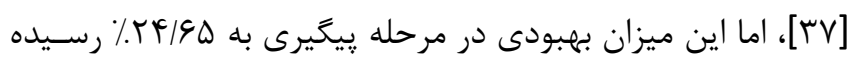

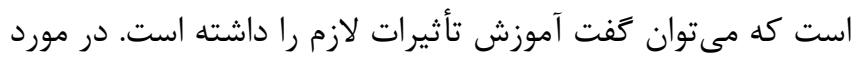

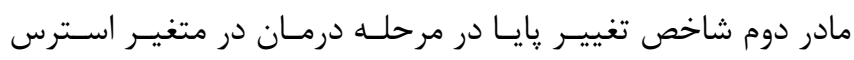

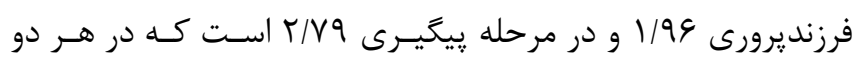

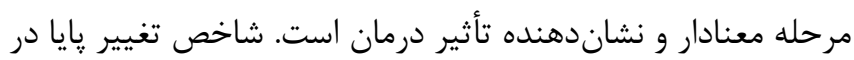

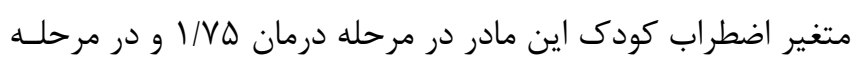

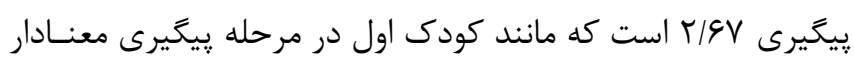

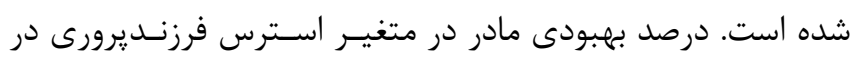

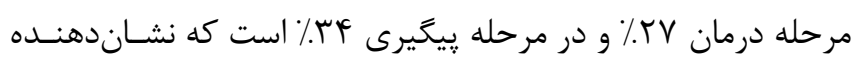

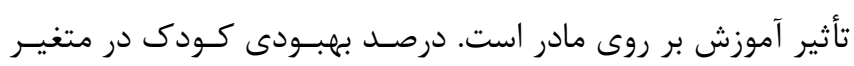

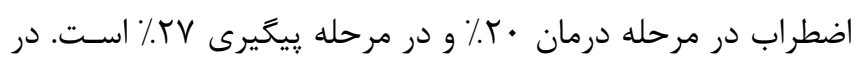

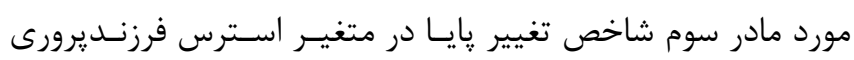

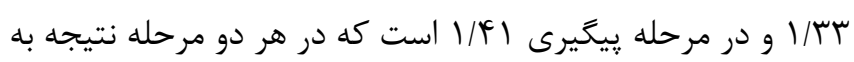

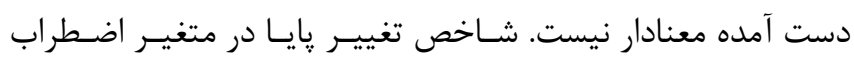

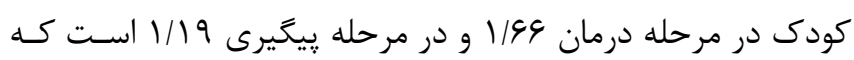

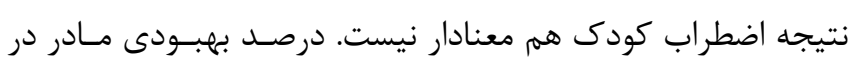

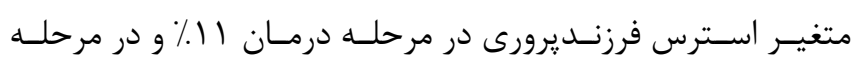

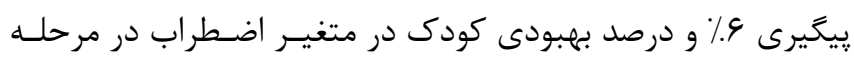

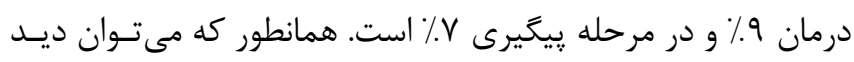

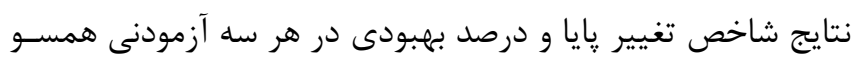
و همر استا با هم است. كام بعدى تحليل ديدارى نمودار هر آزمـودنى اسـت. در تحليـل

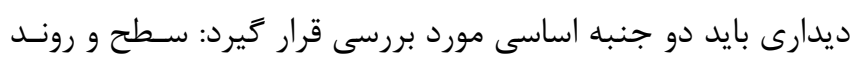

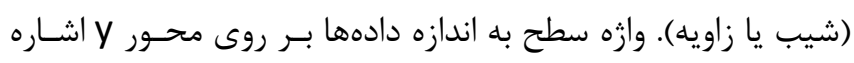

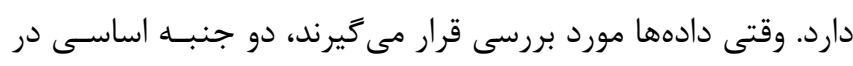

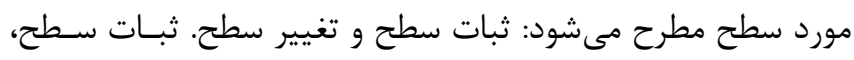

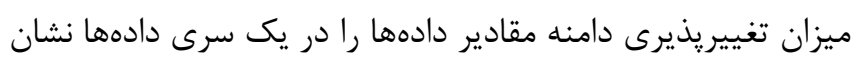

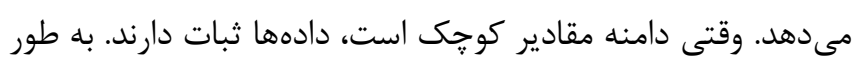

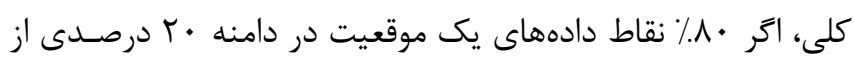

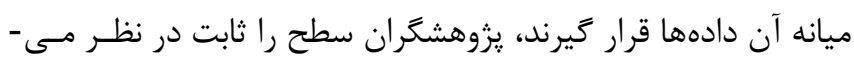


نشريه يزوهشكده علوم بهداشتى جهاددانشكاهى

در جدول شماره ه و تحت عنوان متغيرهاى تحليل ديـدارى درون-

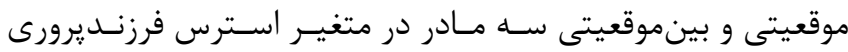

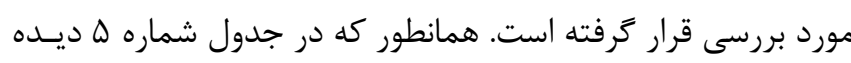

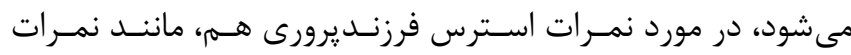

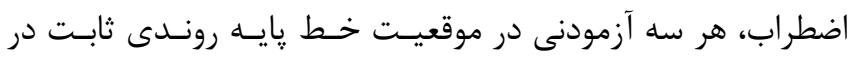

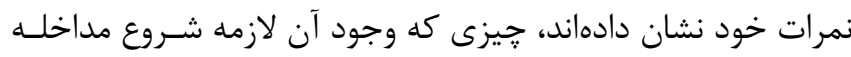

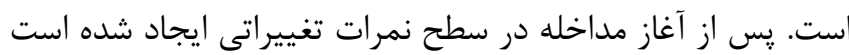
و به طور كلى ميانگين نمرات استرس فرزنديرورى، در آزمودنى اول

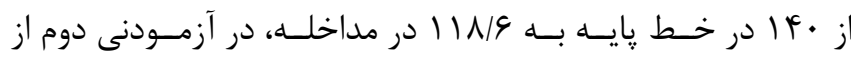

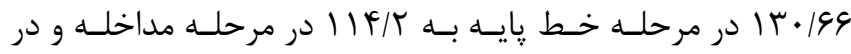

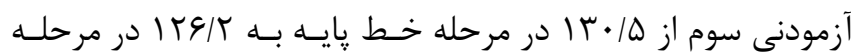

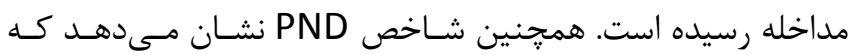

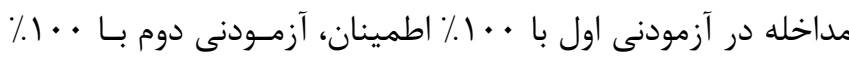

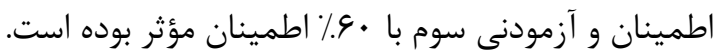

شماره F ديده مىشود هر سه آزمودنى در موقعيت خط يايه روندى

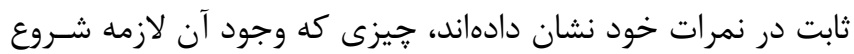
مداخله است. با شروع آموزش تغييرى در روند نمرات ايجاد شـده و وده

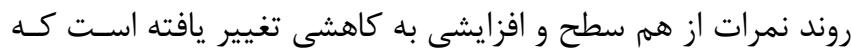

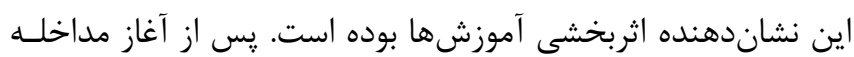

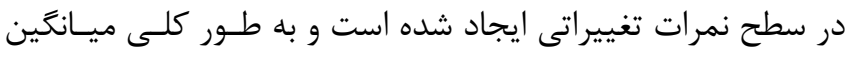

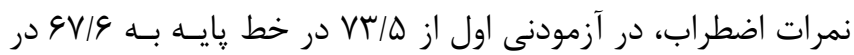

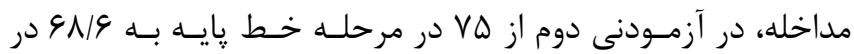

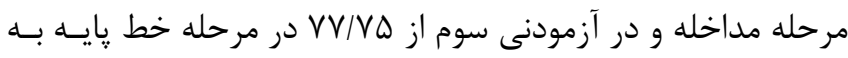
F, FF

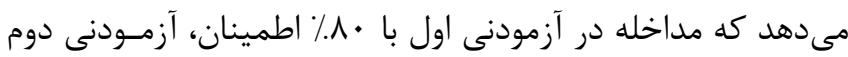

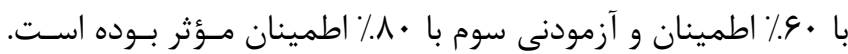
در نمودار شماره r روند تغيير نمرههاى استرس فرزنديرورى والد والدين

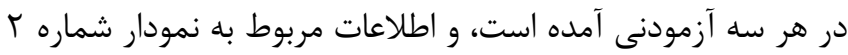

جدولا: جلسات آموزش فرزنديرورى مبتنى بر يذيرش و تعهد

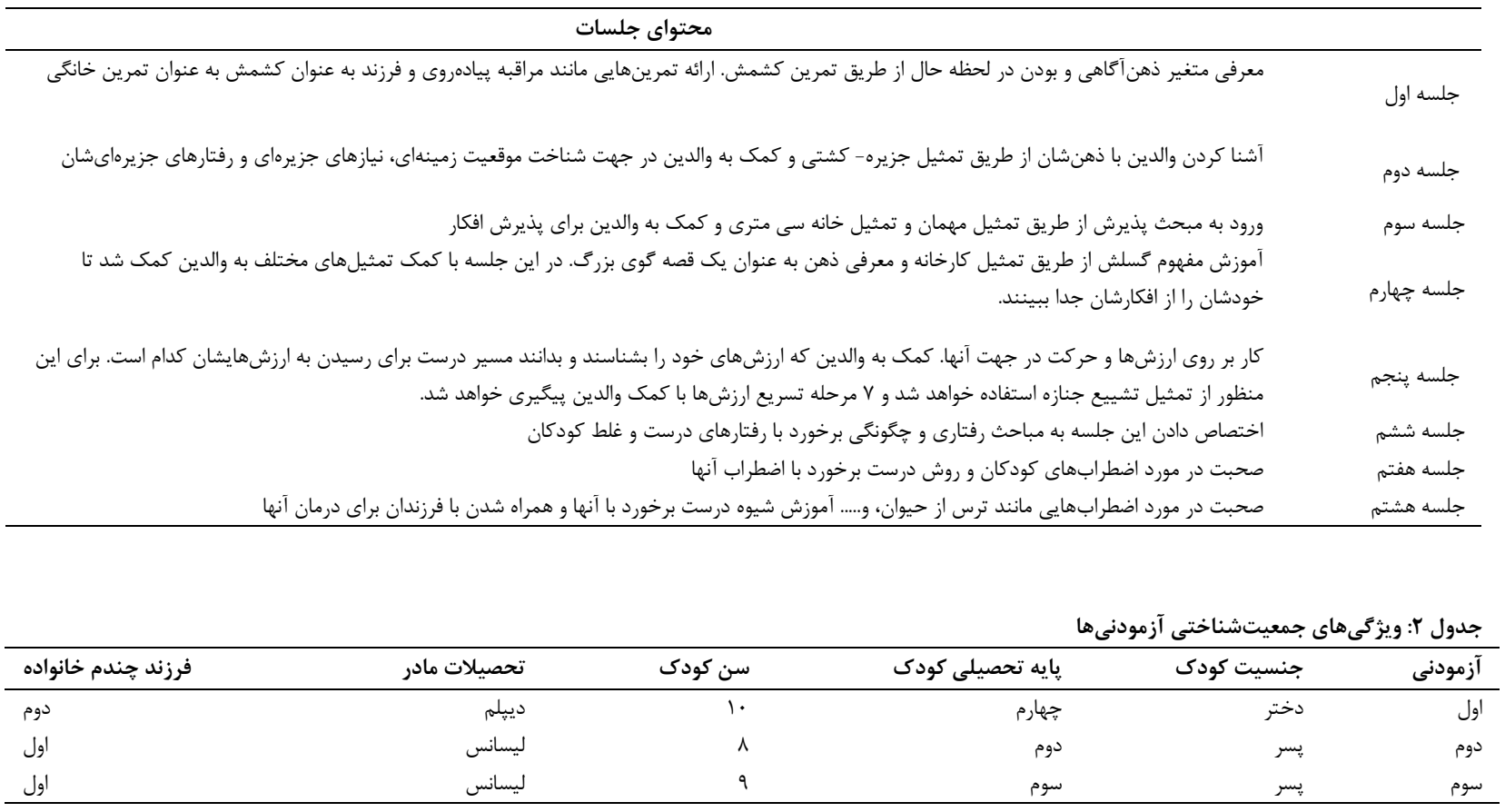


سال بيستم، شماره اول، بهمن ـ-اسفند 99

جدول ب: روند تغيير نمرههاى كودكان در يرسشنامهى اضطراب و نمرههاى مادران در يرسشنامه استرس فرزنديرورى

\begin{tabular}{|c|c|c|c|c|c|c|}
\hline & & & \multirow{2}{*}{\multicolumn{3}{|c|}{ 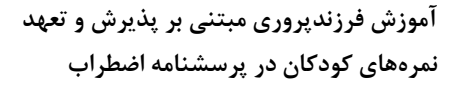 }} & \multirow[b]{3}{*}{ مراحل آموزش } \\
\hline \multicolumn{3}{|c|}{ نمرههاى مادران در يرسشنامه استرس فرزنديرورى } & & & & \\
\hline مادر سوم & مادر دوم & مادر اول & كودى سوم & كودى دوم & كودى اول & \\
\hline IrF & $1 \pi \Delta$ & $|f|$ & VV & Vr & Vr & خط پايهى اول \\
\hline $14 \cdot$ & 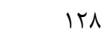 & 149 & v^ & $\vee \wedge$ & ve & 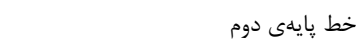 \\
\hline |וT| & ir. & - & VV & ve & - & خط پايهى سوم \\
\hline ITV & - & - & va & - & - & خط پايهى جهارم \\
\hline $14 \cdot 10$ & $14 \cdot 199$ & if. & $V V / V Q$ & vo & $V \Psi / \Delta$ & ميانگَين مراحل خط پايه \\
\hline וr & ira & 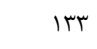 & $\vee \wedge$ & va & $\checkmark \cdot$ & جلسه اول \\
\hline$|r|$ & $|r|$ & ITF & $v f$ & $v \Delta$ & $v^{f}$ & جلسهى سوم \\
\hline ITE & 111 & 110 & Ve & $\checkmark \cdot$ & 99 & جلسهى ششم \\
\hline ITF & $1 \cdot 9$ & 119 & ve & 90 & 90 & جلسهى نهمم \\
\hline 119 & 91 & $1 \cdot \Delta$ & $v \cdot$ & $\Delta \Lambda$ & 4. & جلسه دوازدهم \\
\hline $\mid K E / T$ & $\| x / T$ & $11 N / 9$ & $V \in / 4$ & 9N/9 & $9 V / 9$ & ميانگين مراحل درمان \\
\hline ז & 1/99 & $T / T F$ & $1 / 99$ & $1 / V \Delta$ & $1 / \Delta F$ & شاخص تغيير پايا (درمان) \\
\hline 11 & rV & ro & 9 & r. & iv & درصد بهببودى پس از درمان \\
\hline & r) & & & & س & درصد بهبودى كلى يس از درمان \\
\hline & يِيَيرى & & & بِيخير & & \\
\hline IrV & 19 & 99 & $V F$ & $\Delta r$ & $\Delta \Delta$ & ريخيرى يك ماهd \\
\hline $1 / 41$ & $r / v q$ & r/AF & $1 / 19$ & $r / 9 V$ & $r / T \Delta$ & شاخص تغيير پايا (ييخيرى) \\
\hline 9 & re & rq & v & rr & $r F / 9 D$ & درصد بهبودى ييخيرى \\
\hline & TT/G9 & & & & $19 / \Delta \Delta$ & درصد بهبودى كلى پِ از مرحله يِيَىى \\
\hline
\end{tabular}

جدول f: متغيرهاى تحليل ديدارى درون موقعيتى و بين موقعيتى سه كودى در متغير اضطراب

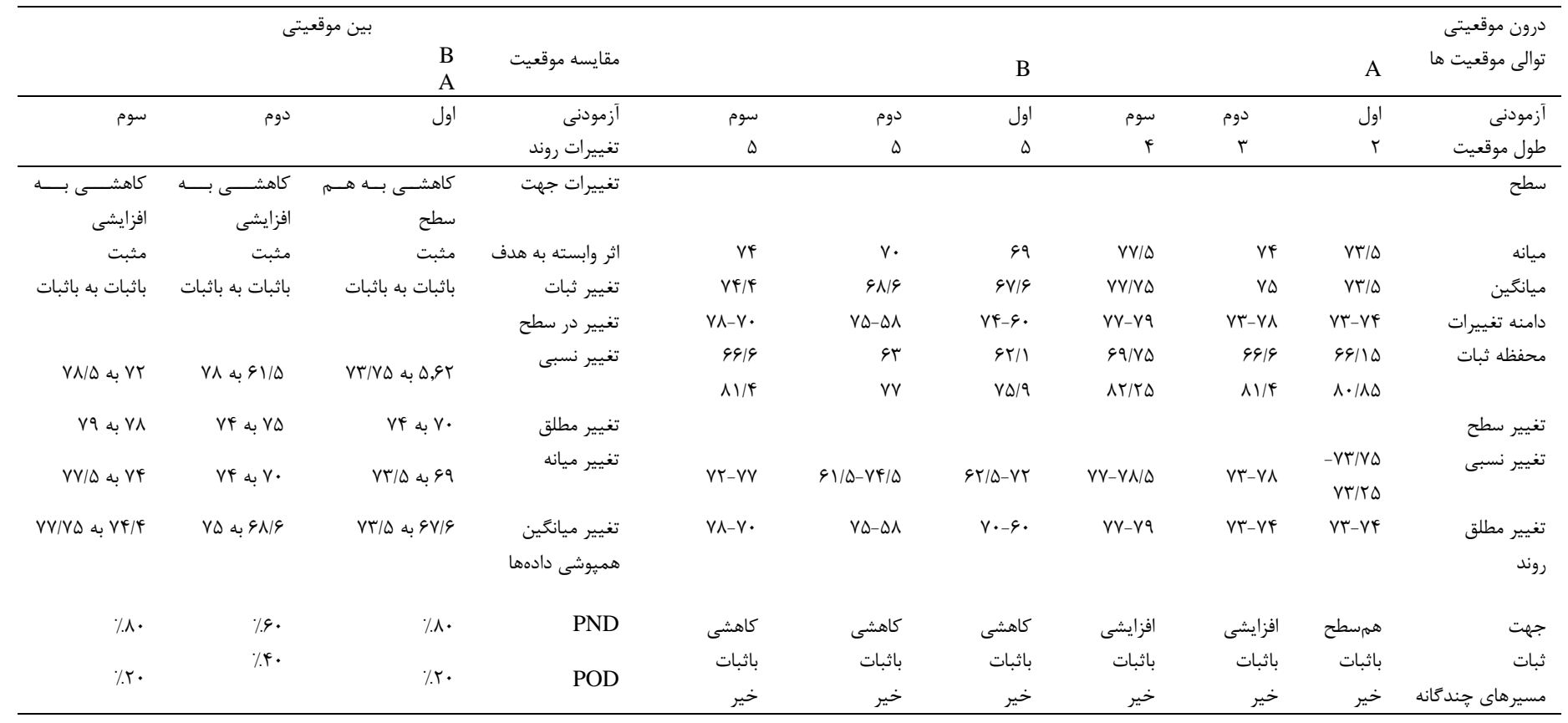




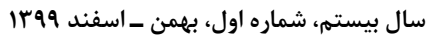

نشريه يزوهشكده علوم بهداشتى جهاددانشكاهى

جدوله: متغيرهاى تحليل ديدارى درون موقعيتى و بين موقعيتى سه مادر در متغير استرس فرزنديرورى

\begin{tabular}{|c|c|c|c|c|c|c|c|c|c|c|}
\hline & & & بين موقعيتى & & & & & & & درون موقعيتى \\
\hline & & B & مقايسه موقعيت & & & $\mathrm{P}$ & & & 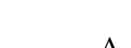 & تـوالى موقعيـت \\
\hline & & A & & & & B & & & A & ها \\
\hline \multirow[t]{2}{*}{ 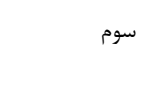 } & \multirow[t]{2}{*}{ دوم } & \multirow[t]{2}{*}{ اول ال ال } & آزمودنى & سوم سوم & دوم & اول & 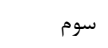 & دوم & اول اول & آزمودنى \\
\hline & & & تغييرات روند & $\Delta$ & $\Delta$ & $\Delta$ & r & r & r & طول موقعيت \\
\hline \multirow{3}{*}{ كاهشى به } & كاهشى به & كاهشى به & تغييرات جهت & & & & & & & سطح \\
\hline & كاهشى & كاهشى & & & & & & & & \\
\hline & مثبت & مثبت & اثر وابسته به هدف & ITS & 111 & 119 & $1 \pi \cdot / 0$ & 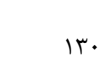 & If. & 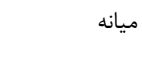 \\
\hline \multirow[t]{2}{*}{ باثبات به باثبات } & \multirow[t]{2}{*}{ باثبات به باثبات } & \multirow[t]{2}{*}{ باثبات به باثبات } & تغيير ثبات & IrE/T & $11 \% / r$ & $11 N / 9$ & $1 r \cdot / 0$ & $15 \cdot 199$ & if. & ميانَين \\
\hline & & & تغيير در سطح & $141-119$ & $\mid r \Delta-9 \Lambda$ & D & $\mid r K-I T V$ & $|r \Delta-| r \Lambda$ & $|4|-1 r q$ & دامنه تغييرات \\
\hline ا & \multirow{2}{*}{ 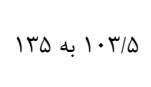 } & \multirow{2}{*}{ 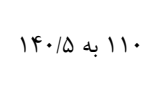 } & \multirow{2}{*}{ تغيير نسبى } & $11 \% / 4$ & $1.9 / \pi$ & $1 \cdot \varphi / 4$ & $\| V / \& \Delta$ & $11 \mathrm{~V}$ & Ire & \multirow[t]{2}{*}{ محفظه ثبات } \\
\hline $\mid r T / \Delta$ & & & & ITN/G & $1 r 9 / 1$ & $\mid r V / 9$ & $\mid \& \Psi / \Delta Q$ & IFT & IDF & \\
\hline$|r|-\mid r v$ & $|r \Delta-| r$. & |rr-וrq & تغيير مطلق & \multirow[b]{2}{*}{$|r| / \Delta-|r|$} & \multirow[b]{2}{*}{$1 \cdot r / \Delta-1 r \mu$} & \multirow[b]{2}{*}{$11 \cdot-1 Y N / \Delta$} & & & & تغيير سطح \\
\hline ع & 111 111 به & |fe & تغيير ميانه & & & & $\begin{array}{r}-\mid r K / \Delta \\
\mid r N / \Delta\end{array}$ & $|r \lambda-| T \Delta$ & $\begin{array}{r}-1 f \cdot / \Delta \\
1 \% q / \Delta\end{array}$ & تغيير نسبى \\
\hline \multirow[t]{2}{*}{ 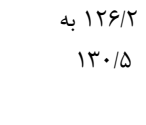 } & 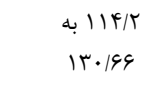 & $1 f \cdot 11 / 1 / 9$ & تغيير ميانكَين & $141-119$ & $\mid r \Delta-91$ & $\mid r r-1 \cdot \Delta$ & $\mid T F-I T V$ & $\mid r \Delta-1 T \cdot$ & $|f|-1 r q$ & تغيير مطلق \\
\hline & \multirow{3}{*}{$\% 1}$. & \multirow{3}{*}{$\% 1}$. & هميوشى دادهها & & & & & & & روند ال \\
\hline \multirow[t]{2}{*}{$\% .9}$. & & & \multirow[t]{2}{*}{ PND } & كاهشى & كاهشى & كاهشى & كاهشى & كاهشى & كاهشى & جهت \\
\hline & & & & باثبات & باثبات & باثبات & باثبات & باثبات & باثبات & 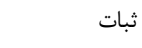 \\
\hline$\% \varphi$ & . & . & POD & خير & خير & خير & خير & خير & خير & مسيرهاى \\
\hline & & & & ي & ي & ي & ي & 'ي & ي & קֶند \\
\hline
\end{tabular}


سال بيستم، شماره اول، بهمن - اسفند 99
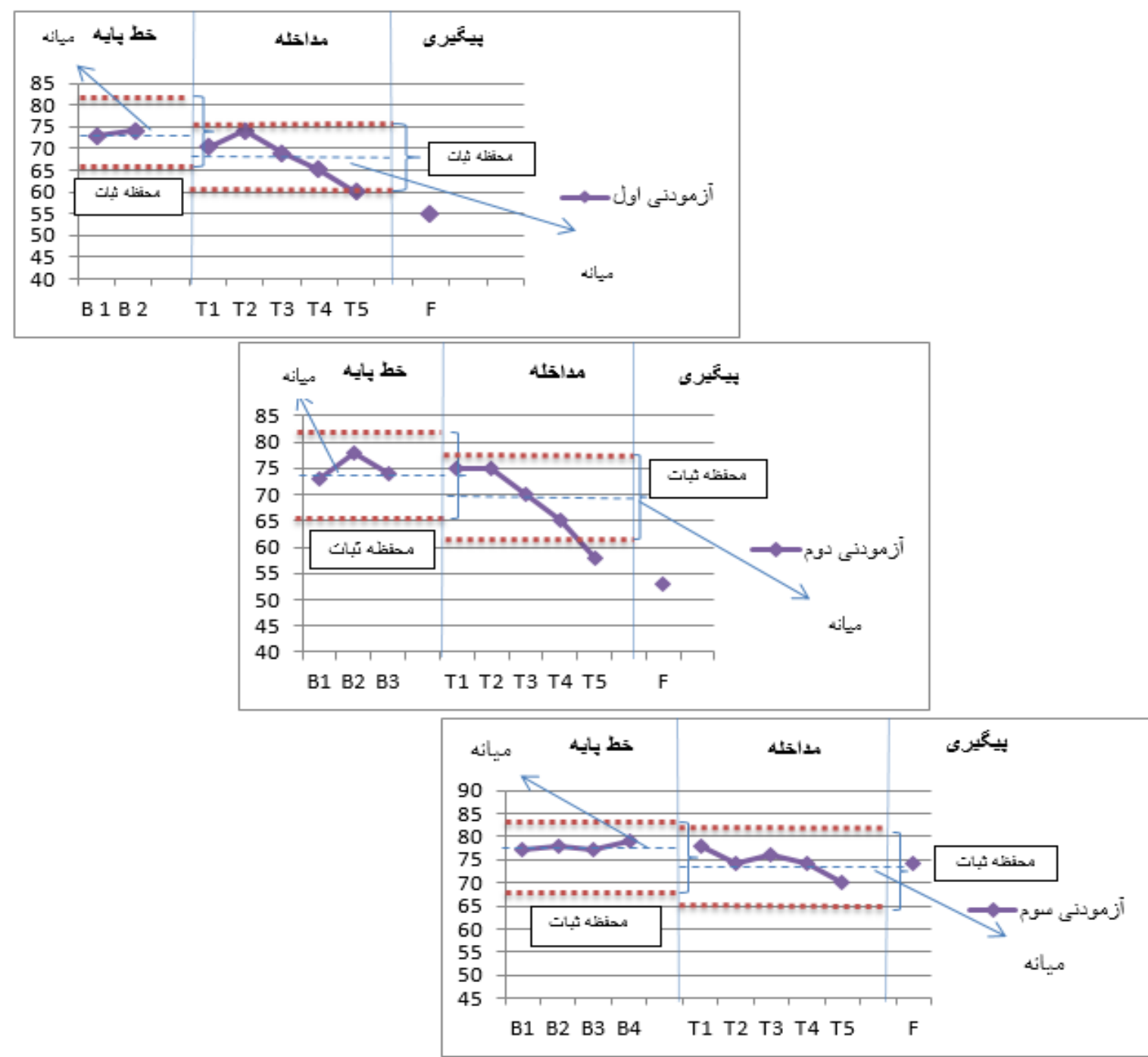

نمودار ا: روند تغيير نمره ایى يرسشنامه اضطراب كودكان در هر سه آزمودنى و ترسيم خط ميانه و محفظه ثبات در موقعيت خط پايه، مداخله 
سال بيستم، شماره اول، بهمن ـاسفند 99\%1\%
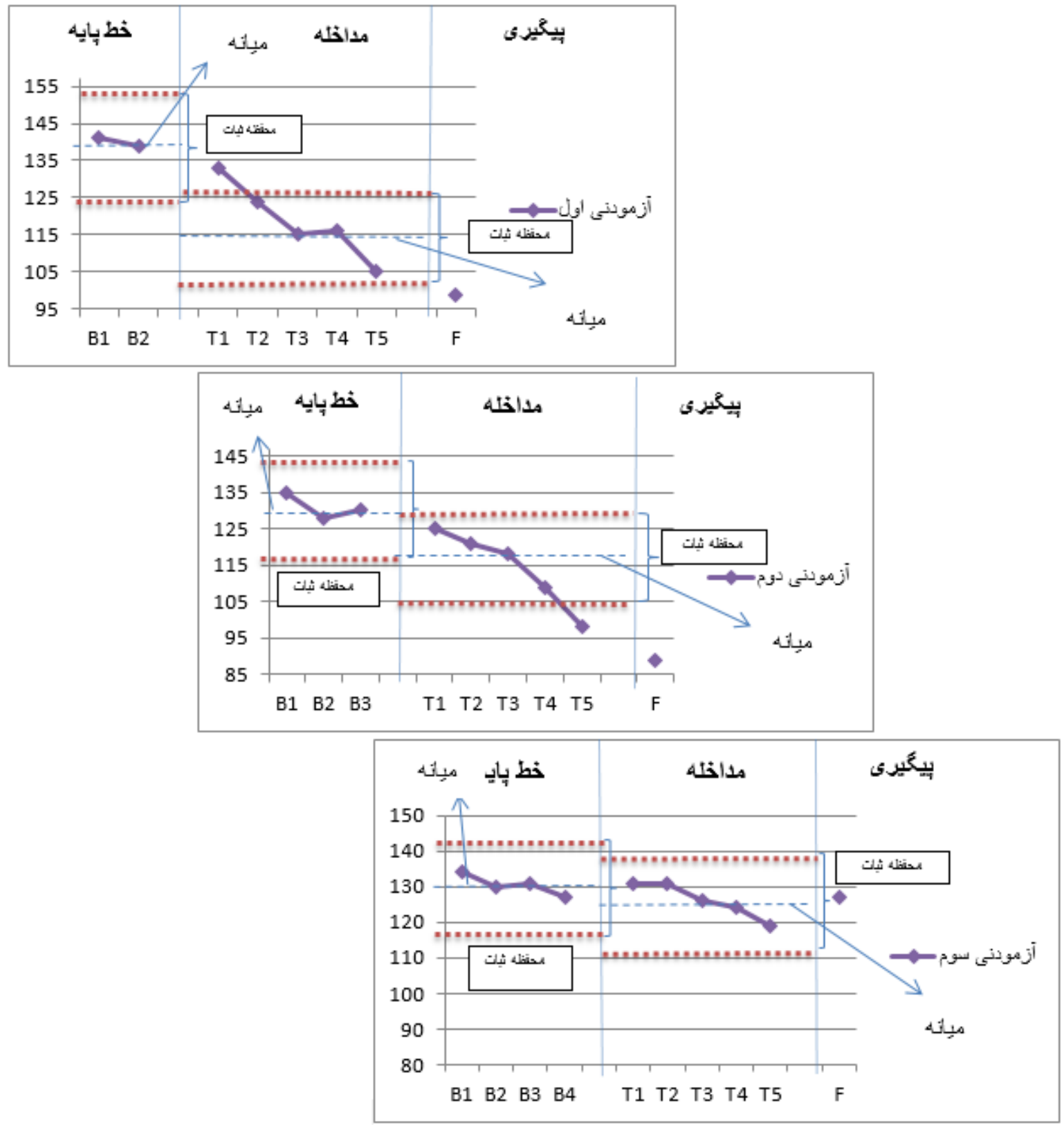

نمودار ז:روند تغيير نمره هاى استرس فرزنديرورى والدين در سه مادر و ترسيم خط ميانه و محفظه ثبات در موقعيت خط پايه و مداخله 


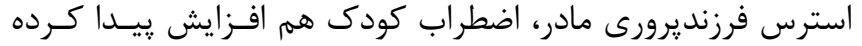

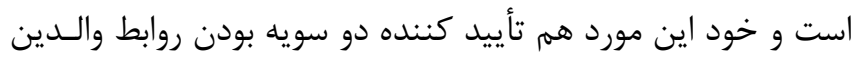

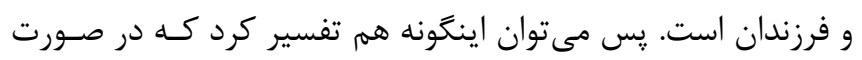
فراهم بودن شرايط براى اين مادر و بهرهمندى از نتايج اين آمـوزش

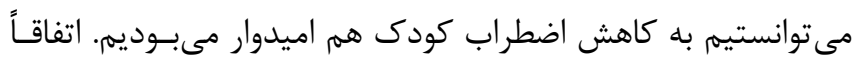

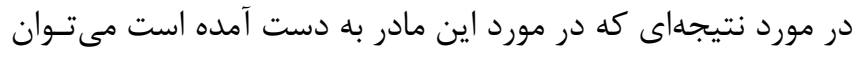

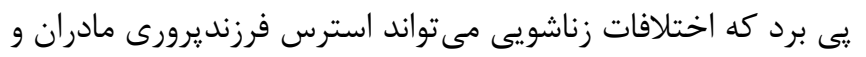

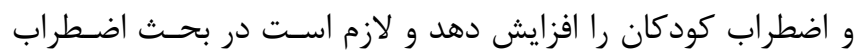

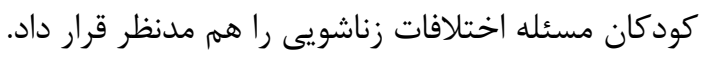

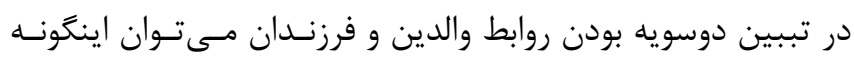

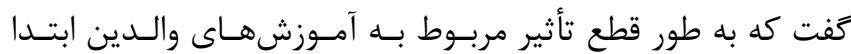

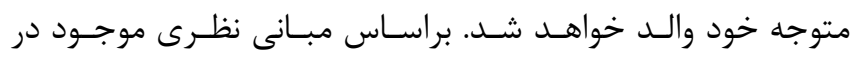

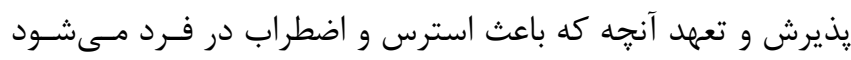
همجوشى شناختى است. همجوشى شناختى به ايـن معناسـت كـهـ

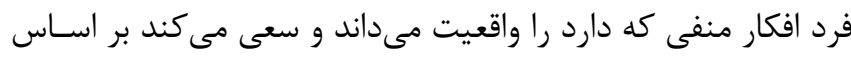

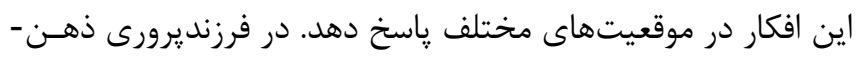

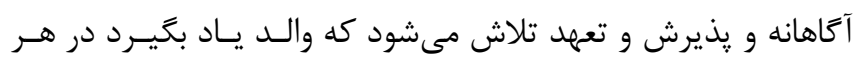

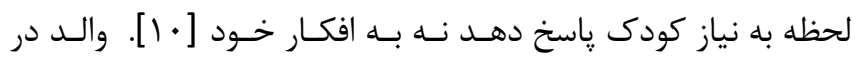

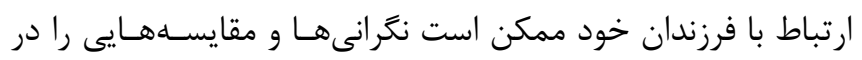

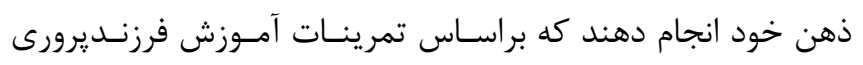

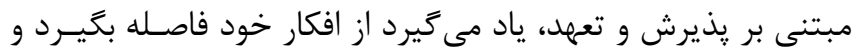

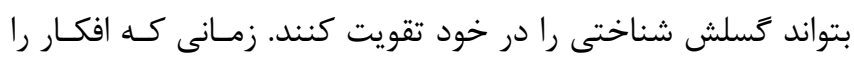

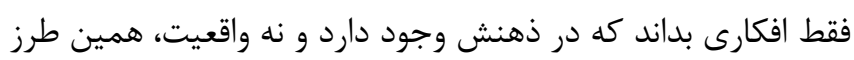

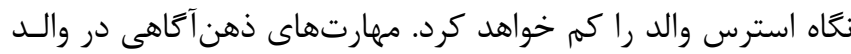

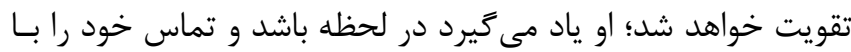

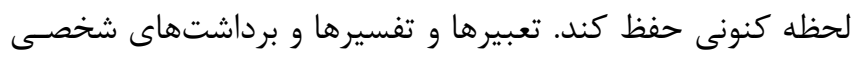

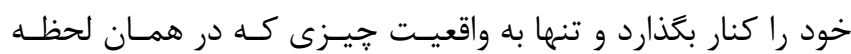

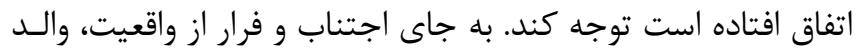

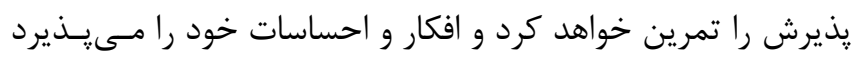

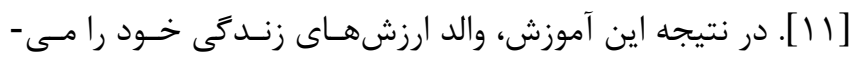

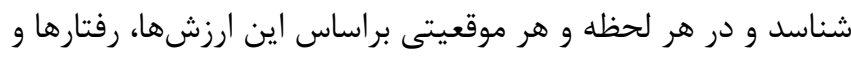

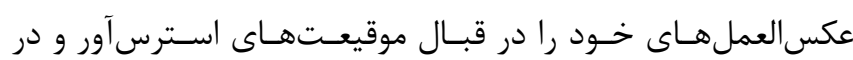

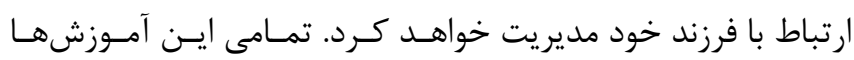

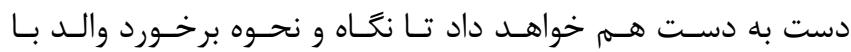

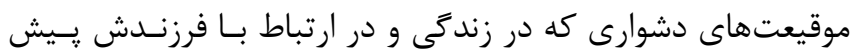

\section{بحث و نتيجه گيرى}

يافتهاى اين يزوهش نتيجه بررسى اثربخشى آموزش فرزنـديرورى

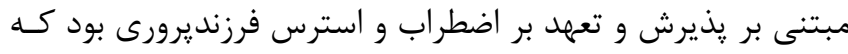

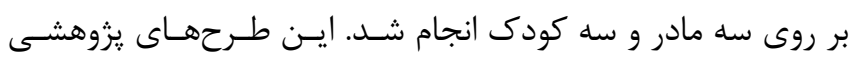

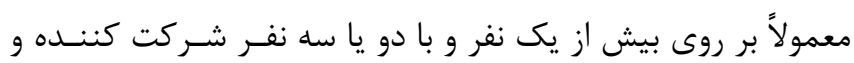

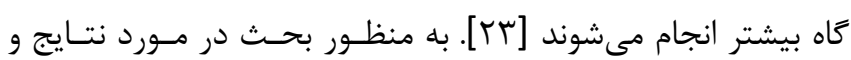

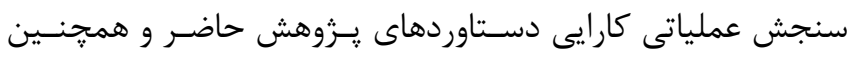

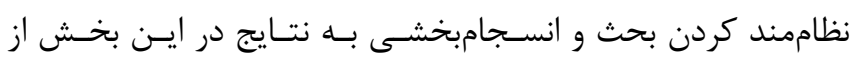

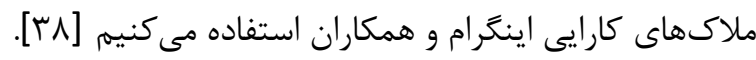

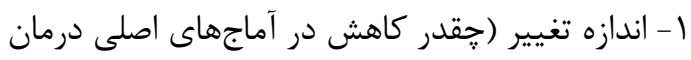

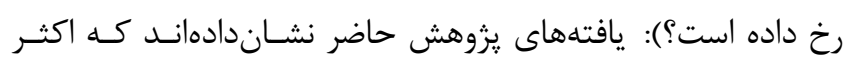

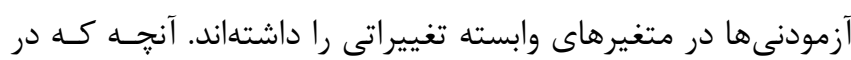

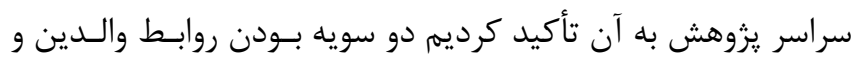

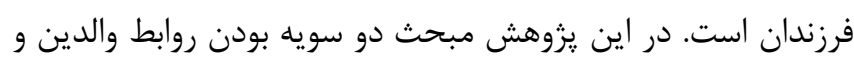

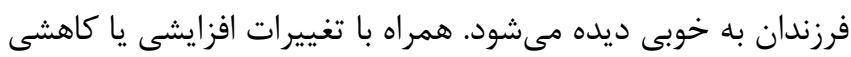

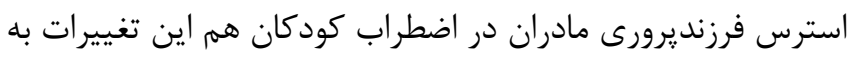

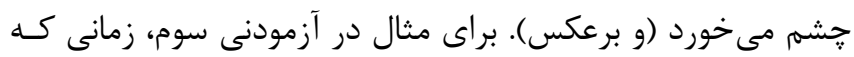

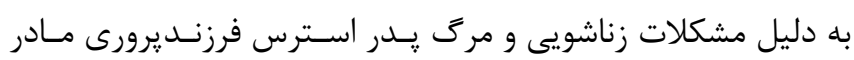

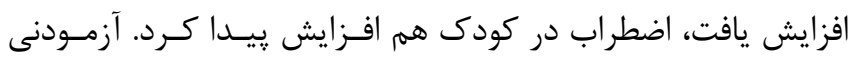

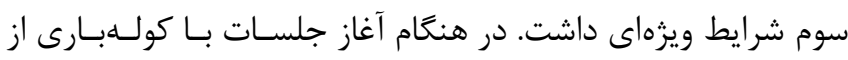

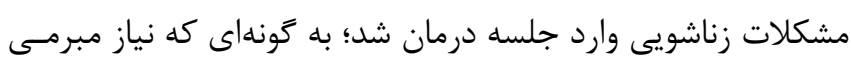

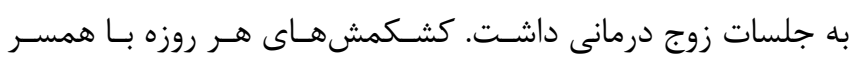

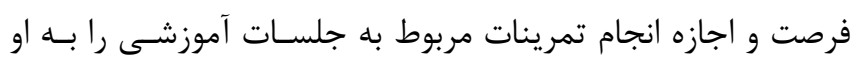

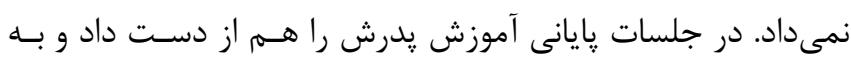

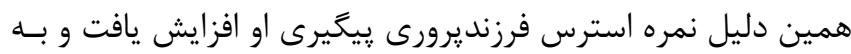

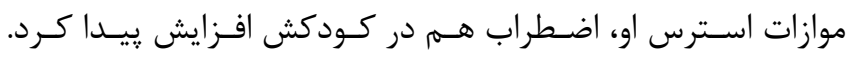

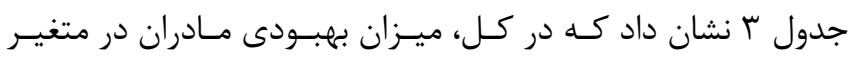

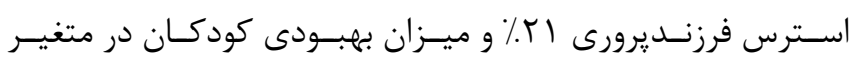

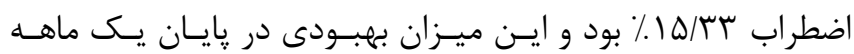

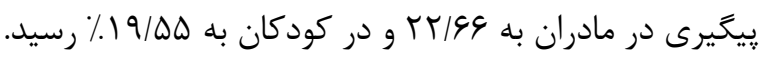

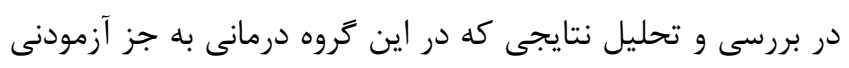

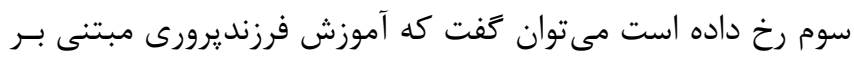

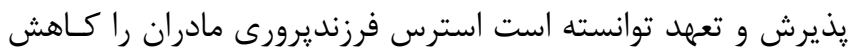

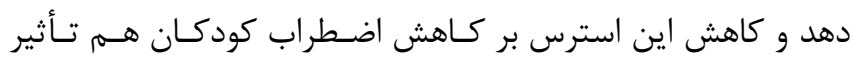

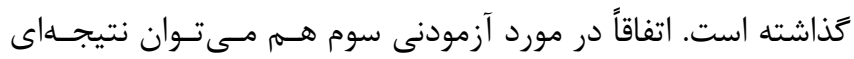

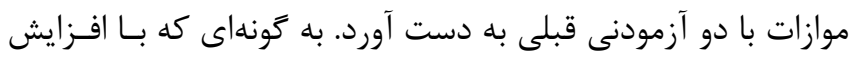


روشها مى كنند. دريغ از اين كه همين روشها اضطراب و اسـترس

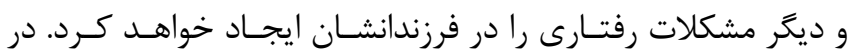

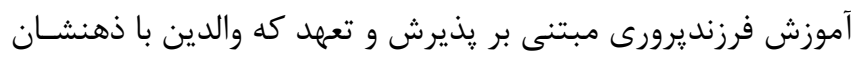

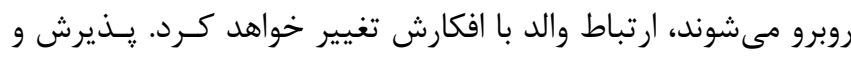
كسلش نسبت به اين افكار در او شكل خواهد كرفت و به والد كمك برك

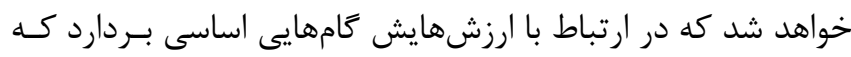

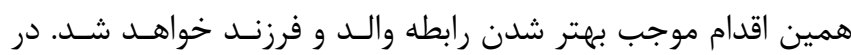

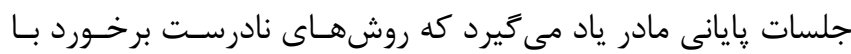

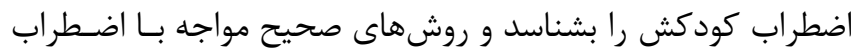

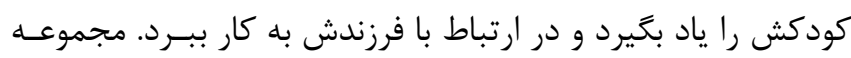

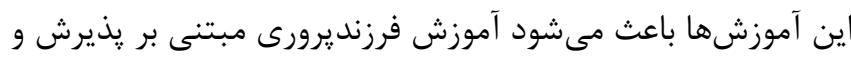

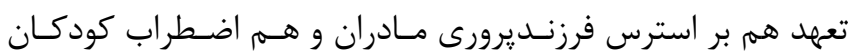

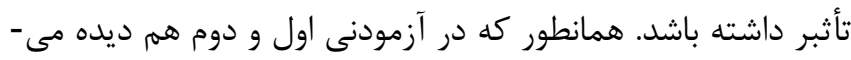

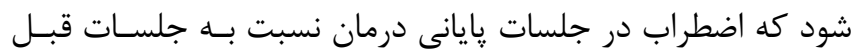

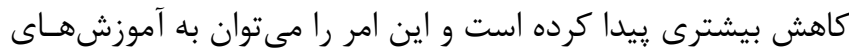

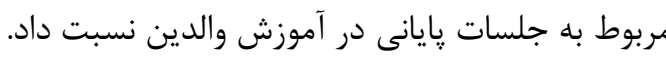

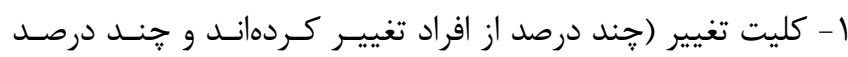

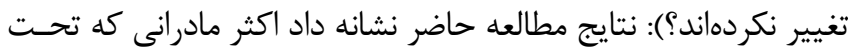

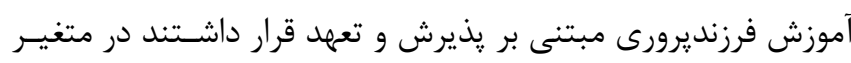

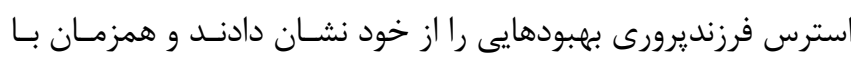

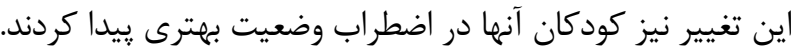

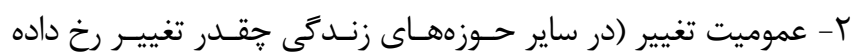

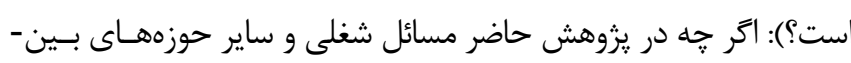

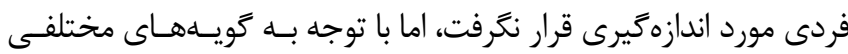

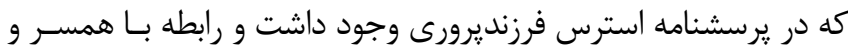

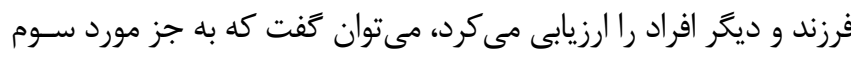

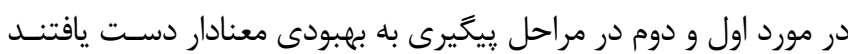
كه نشاندهنده بهبودى در روابط بينفردى است.

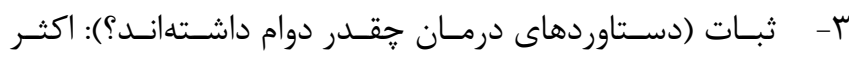

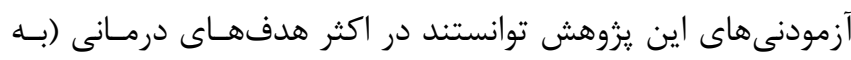
غير از مورد سوم) دستاوردهاى درمانى خود راد در مطالعات يُيخيـرى إنى

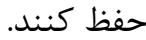

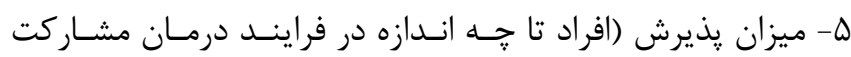

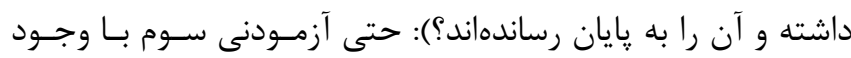

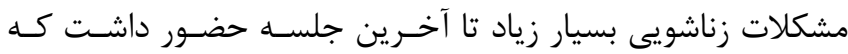

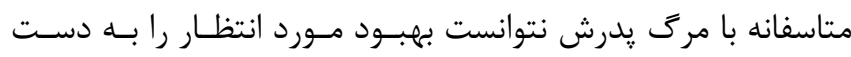

مى آيد تغيير كند و اسـترس فرزنــيرورى او بـه نحـو جشــمكيـرى

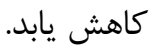

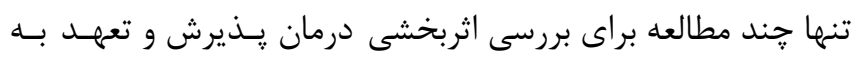
عنوان آموزش والدين منتشر شده است. [ [-1]. از طرفى تحقيقات

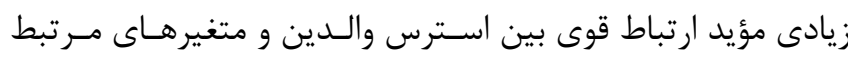

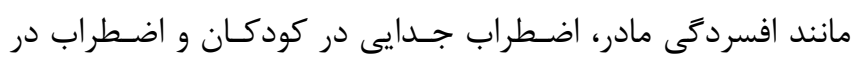

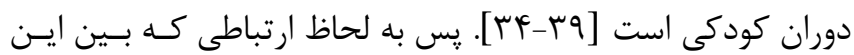

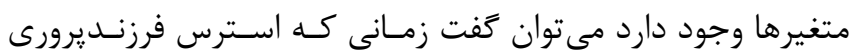

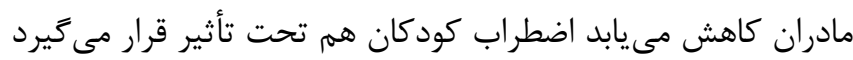

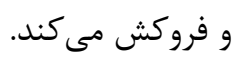

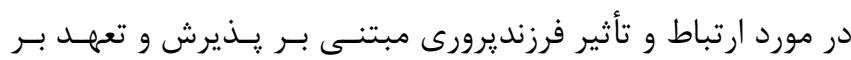

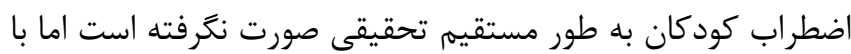

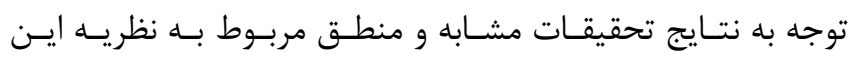

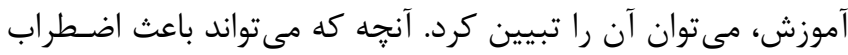

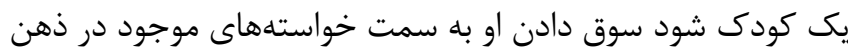

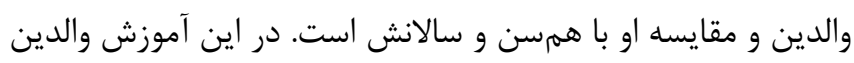

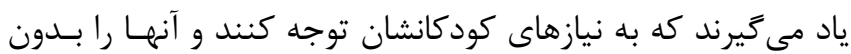

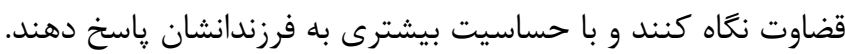

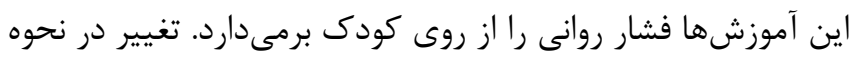

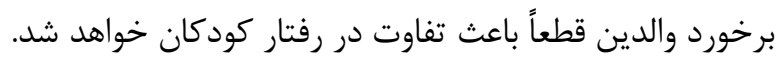

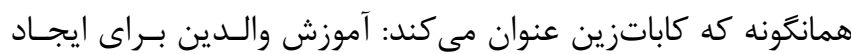

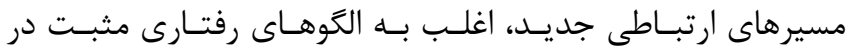

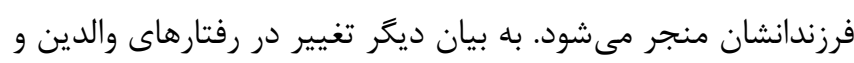

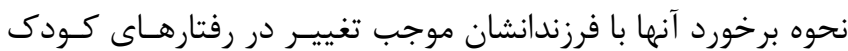

خواهد شد [1 آ].

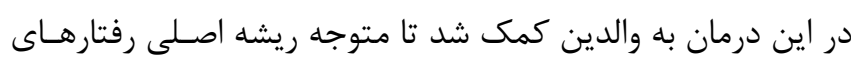
نادرست خود كه همان ذهنشان است شوند. زيرا اعتقاد بر اين است ردان كه حلقه گم شده در فرزنديرورى، ذهن والدين است. گاهى والـدين

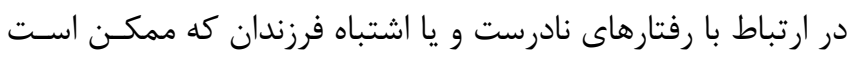

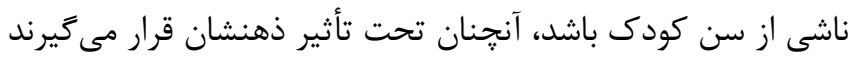

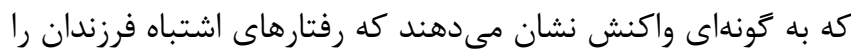

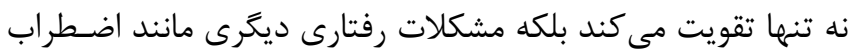

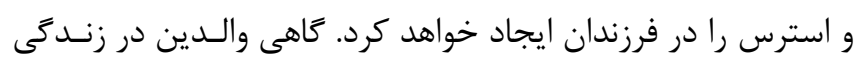
از ارزشهاى خود دور مىشوند و يا اينكه تصور مى كنند راههايى كه براى رسيدن به ارزشهايشان در ارتباط با فرزندشان انتخاب كـردهـ

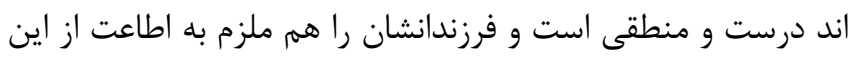




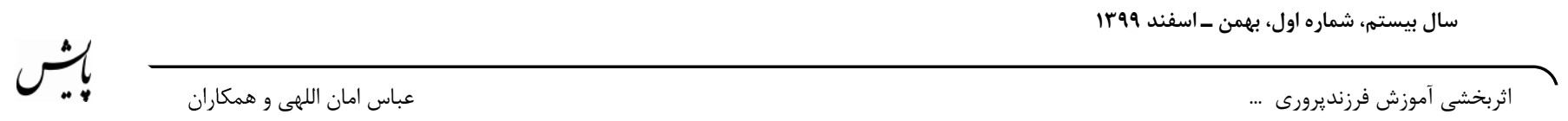

مجدد مطالعه توسط يزوهش گران ديكر، با همـين ابزارهـا ج) تكـرار نظاممند: اجراى همين يزوهش در جمعيت بالينى ديكر و با استفاده

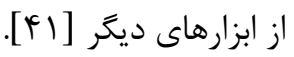

\section{سمهم نويسند}

كوثر تردست: طراحى و اجراى مطالعه، نحارش مقاله

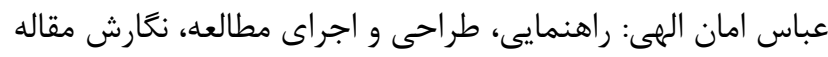
غلامرضا رجبى: همكارى در نغارش مقاله خالد اصلانى: همكارى در نغارش مقاله خديجه شيرالى نيا: همكارى در نغارش مقاله

$$
\begin{aligned}
& \text { تشكر و قدردانى } \\
& \text { از شركت كنندكان كرامى كه صميمانه همكارى لازم را براى اجـراى }
\end{aligned}
$$

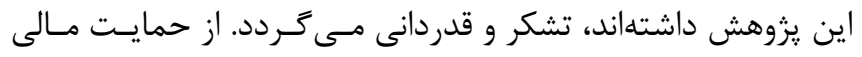

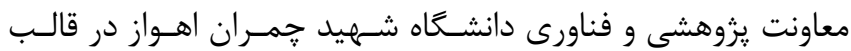

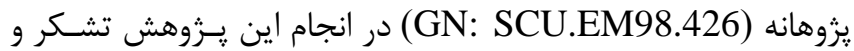

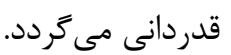

\section{منابع}

1. Polanczyk GV, Salum GA, Sugaya LS, Caye A, \& Rohde LA. Annual research review: a meta-analysis of the worldwide prevalence of mental disorders in children and adolescents. Journal of Child Psychology and Psychiatry 2015: 56, 345-365

2. Wald N, Tadmor-Zisman Y, Shenaar-Golan V, Yatzkar U, Carthy T, \& Apter A. Child-Mother Reappraisal and Child's Anxiety Among Anxious and Non-Clinical Groups. Journal of Child and Family Studies 2020: 29, 1642-1648

3. Nauta MH. Anxiety Disorders in Children and Adolescents: assessment, cognitive behavioural therapy, and predictors of treatment outcome. $\mathrm{PhD}$ Thesis of Philosophy, University of Groningen. 2005

4. Swain J, Hancock K, Dixon A, Koo S, \& Bowman J. Acceptance and Commitment Therapy for anxious children and adolescents: study protocol for a randomized controlled trial. Trials 2013: 14, 1-12

5. Nauta MH, Scholing A, Emmelkamp PMG, \& Minderaa RB. Cognitive-Behavioural Therapy for Children With Anxiety Disorders in a Clinical Setting: No Additional Effect of a Cognitive Parent Training. Journal of the American Academy of Child and Adolescent Psychiatry 2003: 42, 1270-1278

$$
\begin{aligned}
& \text { بياورد. با توجه به اين مسئله مىتوان اين روش رو جـزء روشهـايى }
\end{aligned}
$$

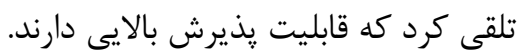

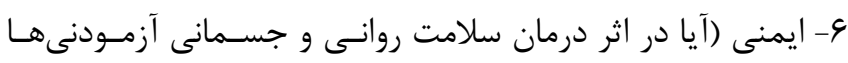

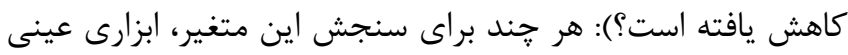

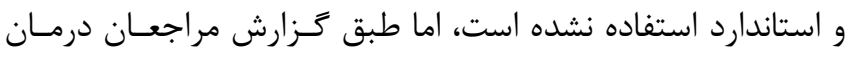

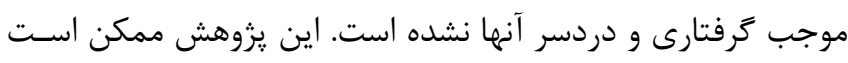

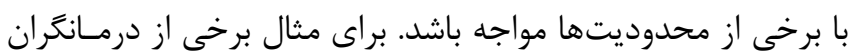

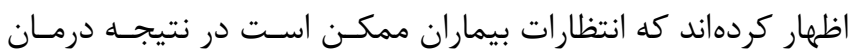

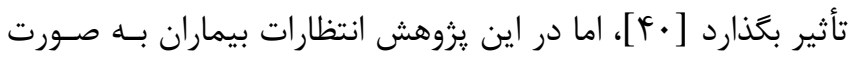

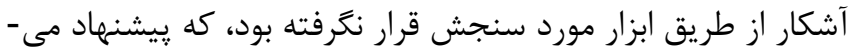

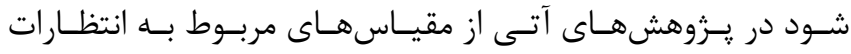

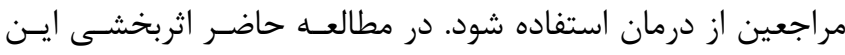

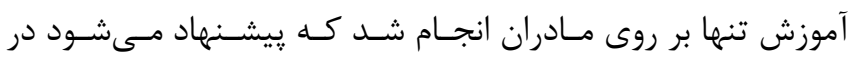

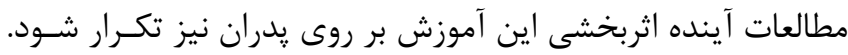

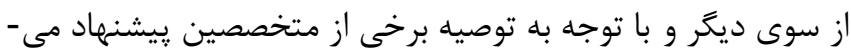

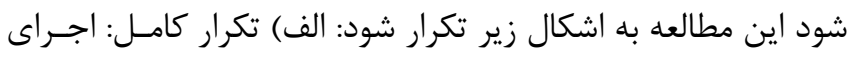

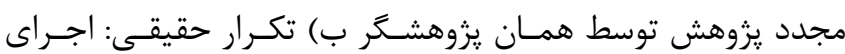

6. Rapee RM. Potential role of childrearing practices in the development of anxiety and depression. Clinical Psychology Review 1997: 17: 47-67

7. McCurry C. Parenting Your Anxious Child with Mindfulness and Acceptance. $1^{\text {st }}$ Edition, New Harbinger Publications, Inc: Oakland, 2009

8. O'Brien K M. Evaluating the effectiveness of a parent training protocol based on an Acceptance and Commitment Therapy philosophy of parenting. Dissertation Prepared for the Degree of Doctor of Philosophy. University of North Texas 2011

9. Blackledge JT, \& Hayes SC. Using acceptance and commitment training in the support of parents of children diagnosed with autism. Child \& Family Behavior Therapy 2006: 28: 1-18

10. Coyne LW, \& Wilson KG. The role of cognitive fusion in impaired parenting: An RFT analysis. International Journal of Psychology and Psychological Therapy 2004: 4: 469-486

11. Greco LA, \& Eifert GH. Treating parentadolescent conflict: Is acceptance the missing link for an integrative family therapy? Cognitive and Behavioral Practice 2004: 11: 305-314 
12. Singh NN, Lancioni GE, Winton ASW, Fisher BC, Wahler RG, Mcaleavey K, Singh J, \& Sabaawi M. Mindful Parenting Decreases Aggression, Noncompliance, and Self-Injury in Children With Autism. Journal of Emotional and Behavioral Disorders 2015: 14: 169-177

13. Bögels SM, Lehtonen A, \& Restifo K. Mindful parenting in mental health care. Mindfulness 2010; 1: 107-120

14. Bögels SM, Hellemans J, van Deursen S, Römer M, \& van der Meulen A. Mindful Parenting in Mental Health Care: Effects on Parental and Child Psychopathology, Parental Stress, Parenting, Coparenting, and Marital Functioning. Mindfulness 2013: 5: 536-551

15. Duncan LG, Coatsworth JD, \& Greenberg MTA Model of Mindful Parenting: Implications for ParentChild Relationships and Prevention Research. Clinical Child and Family Psychology Review 2009: 12: 255270

16. Williams KL, \& Wahler RG. Are mindful parents more authoritative and less authoritarian? An analysis of clinic-referred mothers. Journal of Child and Family Studies 2010: 19: 230 -235

17. Carthy T, Horesh N, Apter A, Edge MD, \& Gross JJ. Emotional reactivity and cognitive regulation in anxious children. Behaviour Research and Therapy 2010: 48, 384-393

18. Wald N, Carthy T, Shenaar-Golan V, TadmorZisman Y, \& Ziskind M. Influence of maternal negative emotion reactivity and cognitive reappraisal on child anxiety disorder. Depression and Anxiety 2018: 35: 353-359

19. Gal M, Borg W, \& Gal J. Quantitative and qualitative research methods in Educational Sciences and Psychology. $2^{\text {th }}$ Edition, Shahid Beheshti University and Samat Publications, Tehran 1995 [Persian]

20. Hayes SC, Barlow DH, \& Nelson-Gray RO. The scientist practitioner: Research and accountability in the age of managed care. $2^{\text {th }}$ Edition, Allyn and Bacon: Boston, 1999

21. Heiman GV. Research method in psychology. $3^{\text {th }}$ Edition, Houghton Mifflin company: Boston, 1998

22. Anderson $\mathrm{CM}, \& \mathrm{Kim} \mathrm{C}$. Evaluating treatment efficacy with single-case designs. In M. C. Roberts \& S. S. Ilardi (Eds.), Handbook of research methods in clinical psychology (pp. 73-91). $1^{\text {st }}$ Edition Malden, MA: Blackwell ,2003

23. Farahani H, abedi A, Aghamohamadi S, \& Kazemi, Z. Applied principles of single case studies in behavioral sciences and medical research. $3^{\text {th }}$ Edition, Psychology and Art 2018, Tehran [Persian]

24. Reynolds CR, \& Richmond BO. What i think and feel: A revised measure of children's manifest anxiety. Journal of Abnormal Child Psychology 1978: 6: 271280

25. Spence SH. Structure of anxiety symptoms among children: a confirmatory factor-analytic study. Journal of Abnormal Psychology 1997: 106: 280.97

26. Spence SH. A measure of anxiety symptoms among children. Behaviour Research and Therapy 1998: 36: 545-66

27. Spence S, Barrett P, \& Turner C. Psychometric properties of the spence children's anxiety scale with young adolescents. Journal of Anxiety Disorders 2003: 17: 605-625

28. Mousavi R, Moradi AR, Farzad V, Mahdavi Harsini E, \& Spence SH. Psychometric Properties of the Spence Children's Anxiety Scale with an Iranian Sample. International Journal of Psychology 2007:1: $17-26$

29. Wang M, Meng Q, Liu L, Liu G. Reliability and Validity of the Spence Children's Anxiety Scale for Parents in Mainland Chinese Children and Adolescents. Child Psychiatry \& Human Development 2015: 47: 830-839

30. Taghavi M, Alishahi M. Validity and reliability Children's Manifest Anxiety Scale. Journal of Psychology 2003: 7: 342-357 [Persian]

31. Stellard P, Velleman R, Langsford J, \& Baldwin S. Coping and psychological distress in children involved in road traffic accidents. British Journal of Clinical Psychology 2011: 41: 197-218

32. Mofrad S, Atefeh Vahid MK, \& Bayanzadeh S. Comparison of worries of anxious and normal children in schools of Dashtestan city. Iranian Journal of Psychiatry and Clinical Psychology 2002: 8: 72-65 [Persian]

33.Carey MP, Faulstich ME, \& Carey TC. Assessment of anxiety in adolescents: Concurrent and factorial validities of the Trait Anxiety scale of Spielberger's State-Trait Anxiety Inventory for Children. Psychological Reports 1994: 75: 331-338

34. Abidin, R. R. Parenting Stress Index, $\mathrm{s}^{\text {th }}$ Edition, Professional Manual, FL: Psychological Assessment Resources, Inc: Odessa, 1995

35. Haskett ME, Ahern LS, Ward CS, \& Allaire JC. Factor structure and validity of the Parenting Stress Index-Short Form. Journal of Clinical Child and Adolescent Psychology 2006: 35: 302-312 
36. Fadaei Z, Dehghani M, Tahmasian K, Farhadei M. Investigating reliability, validity and factor structure of parenting stress- short form in mother's of 7-12 yearold children. Journal of Research in Behavioural Sciences 2010: 8: 81-91 [Persian]

37. Imani M. The effictiveness of Acceptance Based Behavior Therapy and Integrative Behavioral Couple Therapy in reducing distressed couples and General Anxiety Disorder Mahshahr women. PhD Thesis of Counseling 2011 [Persian]

38. Ingram RE, Hayes SC \& Scott W. Empirically supported treatment: A critical analysis. In. Syder, C.R \& Ingram, R.E(Eds). Handbook of psychological change 2000 (pp.40-60), John Wiley \& sons: New York
39. Deater-Deckard K. Parenting stress and child adjustment: Some old hypotheses and new questions. Clinical Psychology. Science and Practice 1998: 5: 314-33

40. Prochaska J, Norcross JC. Theories of psychotherapy. Seyed Mohammadi, Yahya. $3{ }^{\text {th }}$ Edition, Ravan Publishing: Tehran, 2007 [Persian]

41. Hamidpour Hassan. Comparison of the effectiveness of cognitive therapy with schema therapy in the treatment of women with generalized anxiety disorder: symptom reduction, performance improvement, change in mediating variables and the process of symptom change. $\mathrm{PhD}$ Thesis in Clinical Psychology, University of Social Welfare and Rehabilitation Sciences, Tehran, Iran. 2009 [Persian] 